Article

\title{
A PCA-OLS Model for Assessing the Impact of Surface Biophysical Parameters on Land Surface Temperature Variations
}

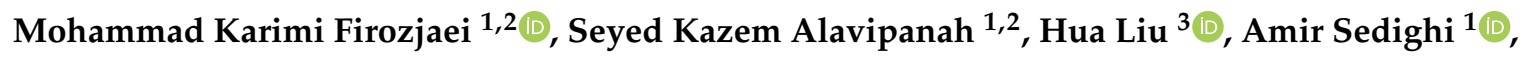 \\ Naeim Mijani ${ }^{1}$, Majid Kiavarz ${ }^{1}$ (D) and Qihao Weng ${ }^{4, *(D)}$ \\ 1 Department of Remote Sensing and GIS, Faculty of Geography, University of Tehran, Tehran 1417853933, Iran \\ 2 Department of Geography, Humboldt University Berlin, Unter den Linden 6, 10099 Berlin, Germany \\ 3 Department of Political Science and Geography, Old Dominion University, Norfolk, VA 23529, USA \\ 4 Center for Urban and Environmental Change, Department of Earth and Environmental Systems, \\ Indiana State University, Terre Haute, IN 47809, USA \\ * Correspondence: qweng@indstate.edu; Tel.: +1-812-237-2255; Fax: +1-812-237-8029
}

Received: 10 July 2019; Accepted: 3 September 2019; Published: 8 September 2019

\begin{abstract}
Analysis of land surface temperature (LST) spatiotemporal variations and characterization of the factors affecting these variations are of great importance in various environmental studies and applications. The aim of this study is to propose an integrated model for characterizing LST spatiotemporal variations and for assessing the impact of surface biophysical parameters on the LST variations. For this purpose, a case study was conducted in Babol City, Iran, during the period of 1985 to 2018. We used 122 images of Landsat 5, 7, and 8, and products of water vapor (MOD07) and daily LST (MOD11A1) from the MODIS sensor of the Terra satellite, as well as soil and air temperature and relative humidity data measured at the local meteorological station over 112 dates for the study. First, a single-channel algorithm was applied to estimate LST, while various spectral indices were computed to represent surface biophysical parameters, which included the normalized difference vegetation index (NDVI), soil-adjusted vegetation index (SAVI), normalized difference water index (NDWI), normalized difference built-up index (NDBI), albedo, brightness, greenness, and wetness from tasseled cap transformation. Next, a principal component analysis (PCA) was conducted to determine the degree of LST variation and the surface biophysical parameters in the temporal dimension at the pixel scale based on Landsat imagery. Finally, the relationship between the first component of the PCA of LST and each surface biophysical parameter was investigated by using the ordinary least squares (OLS) regression with both regional and local optimizations. The results indicated that among the surface biophysical parameters, variations of NDBI, wetness, and greenness had the highest impact on the LST variations with a correlation coefficient of 0.75 , -0.70 , and -0.44 , and RMSE of $0.71,1.03$, and 1.06 , respectively. The impact of NDBI, wetness, and greenness varied geographically, but their variations accounted for $43 \%, 38 \%$, and $19 \%$ of the LST variation, respectively. Furthermore, the correlation coefficient and RMSE between the observed LST variation and modeled LST variation, based on the most influential biophysical factors (NDBI, wetness, and greenness) yielded 0.85 and 1.06 for the regional approach and 0.93 and 0.26 for the local approach, respectively. The results of this study indicated the use of an integrated PCA-OLS model was effective for modeling of various environmental parameters and their relationship with LST. In addition, the PCA-OLS with the local optimization was found to be more efficient than the one with the regional optimization.
\end{abstract}

Keywords: LST variation; surface biophysical parameters; PCA; OLS regression; regional and local optimization 


\section{Introduction}

Land surface temperature (LST) plays a significant role in the energy exchange between land surface and atmosphere [1,2]. Satellite-based thermal infrared (TIR) remote sensing data has been frequently used to obtain LST maps at various spatiotemporal scales [3]. LST has been used in such applications as surface evapotranspiration [4,5], climate studies [6], soil moisture studies [5], vegetation phenology [7], urban microclimate studies [8], surface water cycle [9], and fire monitoring [10].

LST varies in both spatial and temporal dimensions, and is affected by various environmental variables [11,12], including temporal characteristics (hours of day and day of year), geographic location, topographic factors (elevation, slope, and aspect), thermal surface properties (emissivity and thermal inertia), biophysical parameters (wetness, vegetation, brightness, and albedo), soil texture, meteorological parameters (wind, water vapor, and air pressure), and sub-surface features (geothermal, hydrothermal, and volcanic areas) [2,13,14]. Land use and land cover (LULC) change is one of the most fundamental human modifications to the terrestrial ecosystem, which has a significant influence on the local, regional, and global environment. LULC changes can cause changes in surface biophysical parameters and LST $[15,16]$. LST variation is one of the most influential factors in surface soil moisture [5], climate change [6], drought [17], evapotranspiration [5], global warming [18], Urban Heat Island Intensity (UHII) [8,19], energy consumption [20], and thermal comfort [21]. Therefore, it is important to study the LST variation and associated parameters [2]. The influences of LULC changes on LST have been investigated in many previous studies [15,22]. Some studies examined the influence of surface biophysical parameters on LST based on the investigation of such biophysical variables as the normalized difference vegetation index (NDVI) [7], normalized difference built-up index (NDBI) [23], and surface topography [3]. Other studies investigated the roles of different biophysical variables on the spatial distribution of LSTs [24-27]. Zhan et al. provided an overview of multiple indices for modeling the spatial variation of LSTs [28]. Hutengs and Vohland modeled LST and its relationships with digital elevation data, surface reflectance data, and land cover maps [29]. Similarly, Sismanidis et al. employed NDVI, DEM, albedo, and land surface emissivity for LST modeling [30]. He et al. provided a systematic analysis of the environmental parameters on LST [31].

In recent studies, various models such as artificial neural networks (ANN), support vector regression, gradient boosting machine (GBM), random forest (RF), partial least squares (PLS), and ordinary least squares (OLS) have been applied to investigate the impact of biophysical parameters on LST $[3,13,14,32]$. Regression techniques were also employed in studying LST variations in some studies $[13,32,33]$. However, there are notable limitations in applying regression techniques in remote sensing studies [2,27]. One of the limitations is that regression analyses are often used with a regional approach in which a set of parameters are uniformly applied to the entire study area. A basic assumption in such analyses is that relationships are static over different regions of the study area. This assumption may often be indefensible when a remote sensing study covers a large area, where a local approach would be more suitable [13,34,35]. More significantly, in most of the previous studies, the relationship between LST variations and biophysical parameters was investigated in the spatial dimension only $[32,33,36]$. Few studies have examined LST variation and its relationship with biophysical parameters in both spatial and temporal dimensions with an integrated model.

The principal components analysis (PCA) is a multivariate statistical method and an important tool for multi temporal analysis [37-39]. The PCA method is a linear orthogonal transformation that transforms the original dataset into a compressed dataset of uncorrelated variables known as the principal components (PCs). The PCs represent the important information of the primary dataset [40-42]. When a PCA is applied to remote sensing images for temporal analysis, it calculates new values for each pixel of the original images to generate PCs.

The information of each PC image will be varied based on the properties of the primary dataset (temporal resolution, spatial resolution, time period of the time series, and extent of study area) [43-45]. However, PC1 contains the major information of variability in the time series, whereas the other PCs contain the seasonal variability of the time series, each related to a certain parameter 
or parameters [46-48]. PCA has been widely used for temporal analysis, and compares well to other methods widely used for temporal analysis in many studies because of its simple implementation and ability to enhance information $[43,49]$.

The aim of this study is to propose a spatiotemporal integrated model for assessing the impact of surface biophysical parameters variations on LST variations, by conducting a case study in Babol City, Iran. Landsat images acquired between years 1985 and 2018 were used to derive the biophysical parameters and to analyze their relationship with LSTs derived from Landsat imagery. For this purpose, two basic steps were taken: (1) conducting a PCA to determine LST and biophysical parameters variations in the temporal dimension at the pixel scale; and (2) applying the spatial moving window method to investigate the impact of surface biophysical parameters variations on LST variations, based on the OLS regression with both regional and local approaches.

\section{Study Area}

The study area included the City of Babol and its suburbs with an area of approximately 10,062 hectares $(10.32 \mathrm{~km} \times 9.75 \mathrm{~km})$. Geographically, the study area is located between $52^{\circ} 37^{\prime} 31^{\prime \prime}$ and $52^{\circ} 44^{\prime} 25^{\prime \prime} \mathrm{E}$ in longitude and between $36^{\circ} 30^{\prime} 14^{\prime \prime}$ and $36^{\circ} 35^{\prime} 30^{\prime \prime} \mathrm{N}$ in latitude. It is distanced $15 \mathrm{~km}$ from the Caspian Sea, $20 \mathrm{~km}$ from the Hyrcanian forests, $45 \mathrm{~km}$ from the Alborz Mountains, and $210 \mathrm{~km}$ from the Tehran (capital of Iran). The study location is on the south side of the Caspian Sea, as shown in Figure 1. The average elevation of the study area is about $2 \mathrm{~m}$ below sea level with a temperate and humid climate. The minimum and maximum values of elevation and slope of study area are $-3-10 \mathrm{~m}$, and $0^{\circ}-5^{\circ}$, respectively. For this reason, the spatial variation of climatic and topography parameters impacting on the spatial variations of LST is relative. The City of Babol is the most populated city in Mazandaran Province, and the second most populated city in northern Iran. The region's population has grown by more than $20 \%$ from 1985 to 2017 [19]. The population growth has led to built-up expansion of the city and changed agricultural lands and green spaces around the city [50,51]. The results of previous studies indicate that the built-up land increased from 19\% of the total area in 1985 to $36.52 \%$ in 2015 . Land-use change predictions for the next 30 years indicate that the urban expansion will continue into the surrounding natural environments, and consequently, LST and biophysical parameters would also be affected.

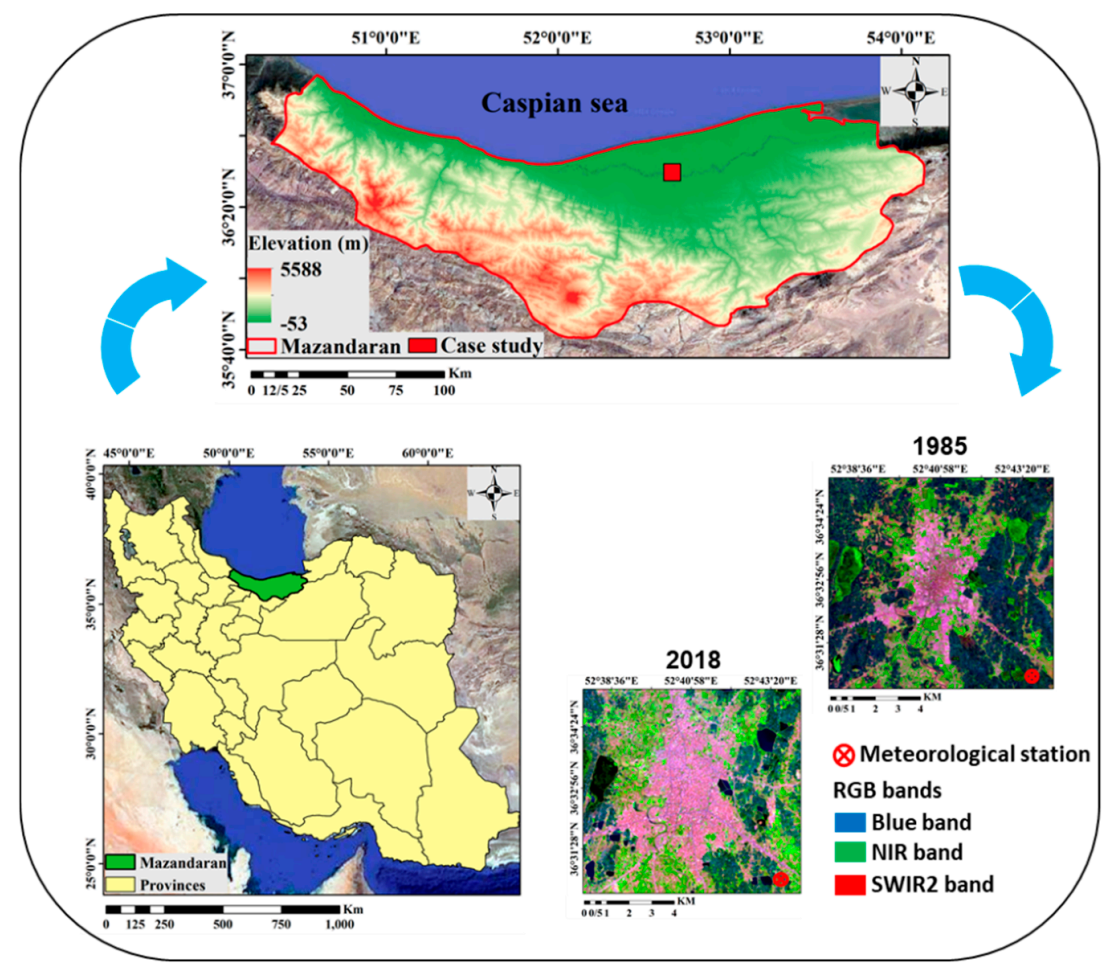

Figure 1. Location of the study area. 


\section{Data and Methods}

\subsection{Data}

In this study, reflective and thermal bands of satellite images acquired by Landsat 5, 7, and 8 were used to calculate LST and surface biophysical parameters. The spatial resolution of the reflectivity and thermal bands of the Landsat 8 images are 30 and $100 \mathrm{~m}$, and Landsat 5 are 30 and $120 \mathrm{~m}$, respectively. These images were georeferenced and located in zone $39^{\circ} \mathrm{N}$ of the Universal Transverse Mercator (UTM) coordinate system. All Landsat images (path/row 168/34) are available at the United States Geological Survey (USGS) website [52]. All selected Landsat images contained less than $10 \%$ cloud cover. Overall, 44 images of Landsat 5, 42 images of Landsat 7, and 26 images of Landsat 8 were used in this study. The number of images in some years is low due to the cloudiness of the study area. Figure 2 shows the time distribution of utilized Landsat images used. The number of images in the winter season and in some years is low due to the cloudiness of the study area.

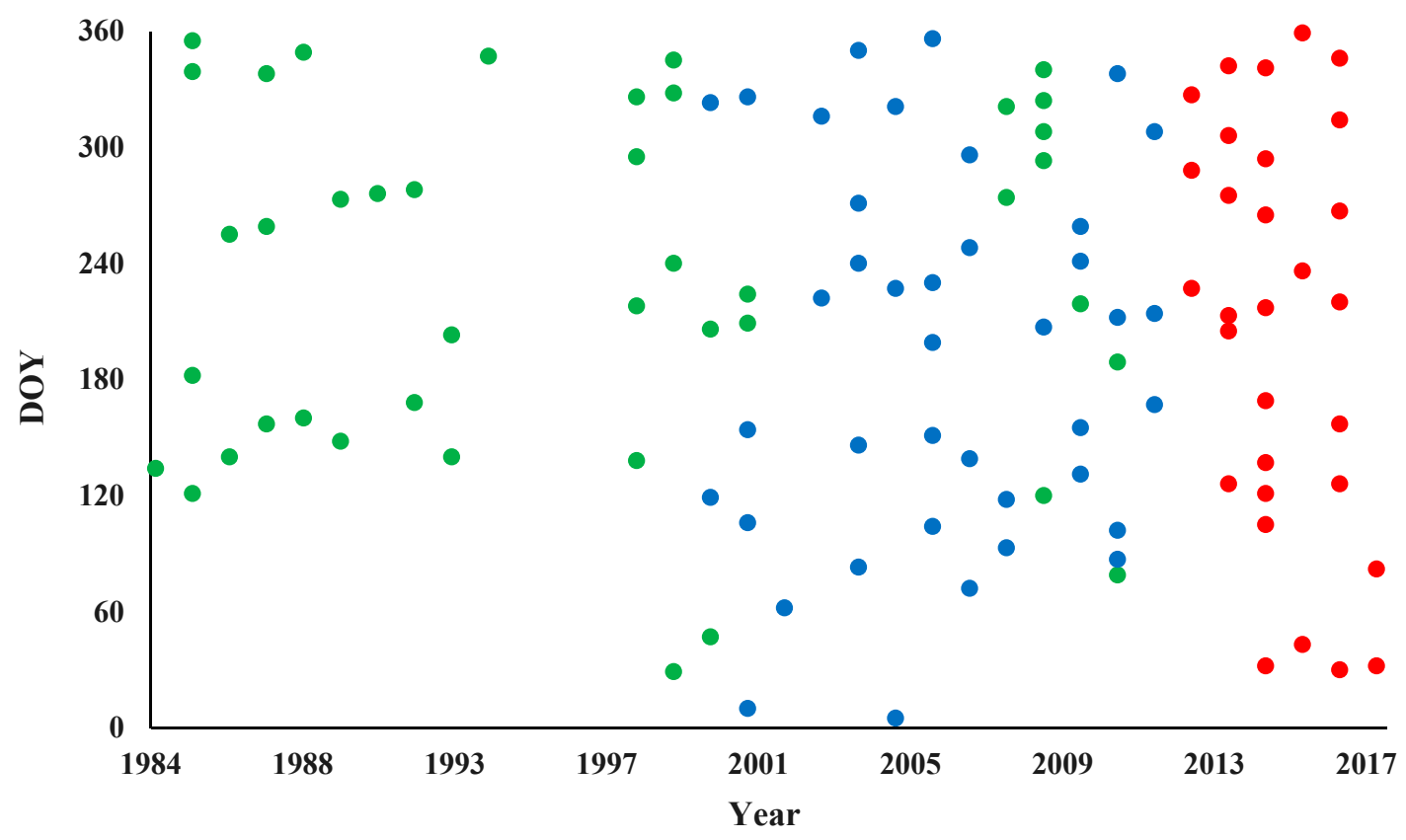

Figure 2. Landsat data for current study. Color code: Green, Landsat 5; Blue, Landsat 7; and Red, Landsat 8.

The daily water vapor (MOD07) with a spatial resolution of $5000 \mathrm{~m}$ and LST (MOD11A1) products of the Moderate Resolution Imaging Spectroradiometer (MODIS) sensor of the Terra satellite [53] with a spatial resolution of $1000 \mathrm{~m}$ within the period of 2001-2018, as well as soil and air temperature and relative humidity data measured at the a meteorological station within the period of 1985-2018 of the study area, were used to prepare and evaluate the LST-maps-derived Landsat imagery [54]. The recording time of the climate data and the MODIS products was simultaneous with the Landsat overpass during the 1985-2018. The type of meteorological station in the study area was a synoptic station. This station operates nonstop and hourly to record data and send meteorological reports. At this station, parameters such as air temperature, humidity, air pressure, wind speed and direction, rainfall, the LST, and the earth's subsurface temperatures from $5 \mathrm{~cm}$ to $1 \mathrm{~m}$ from the ground level are measured and recorded. The meteorological station is located outside of the city and in an area with homogeneous surface conditions (flatness and grassland, see Figure 1). 


\subsection{Methods}

The methodology shown in Figure 3 presents a spatiotemporal integrated model for characterizing the impact of the surface biophysical parameters variations on LST variations. Firstly, the utilized satellite images were preprocessed (atmospheric corrections, radiometric corrections, restoring the values of missed pixels for scan line corrector (SLC)-off images, and a subset of the study area). Secondly, the LST and various surface biophysical parameters were extracted based on reflective and thermal bands of Landsat imagery, MODIS product, and meteorological data for the period from 1985 to 2018. Thirdly, the principal component analysis (PCA) technique was employed to determine the degree of variation of the LST and surface biophysical parameters in the temporal dimension at the pixel scale. Fourthly, the impact of the surface biophysical parameters variations on LST variations was assessed by investigating the relationship between the first principal components (PC1s) of LST and each surface biophysical parameter at the regional and pixel scales by using ordinary least squares (OLS) regression. Finally, the relationship between the LST PC1s and effective surface biophysical parameters was analyzed using multivariate OLS regression with regional and local approaches.
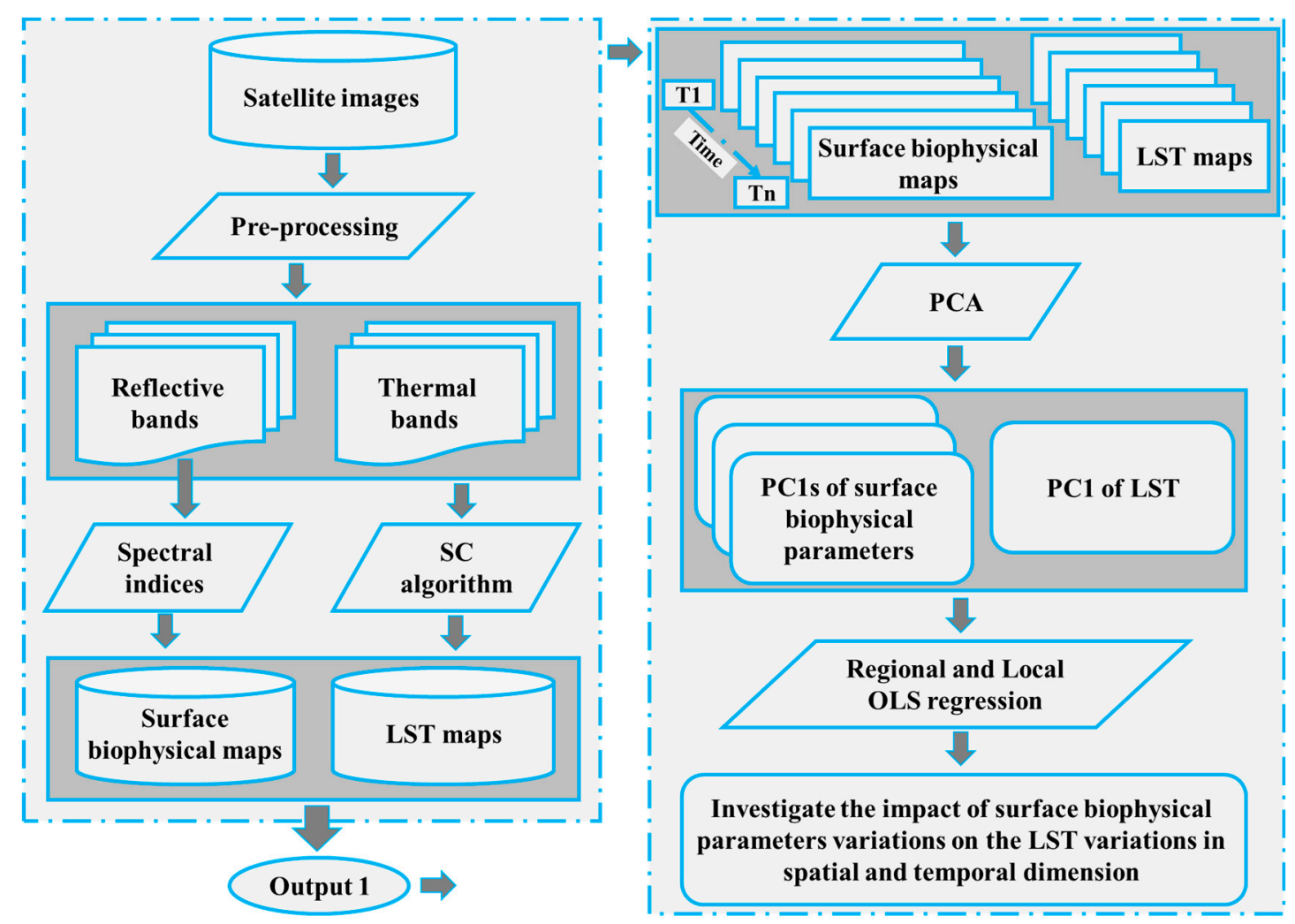

Figure 3. The flowchart of the analytical procedures.

\subsubsection{Image Preprocessing}

In this study, the fast line-of-sight atmospheric analysis of hypercubes (FLAASH) model was used for atmospheric correction. This module uses the atmospheric radiative transfer (MODTRAN6) model for the atmospheric correction. To run FLAASH, some parameters, including satellite overpass time, sensor altitude, geographical location, specific atmospheric model related to the region, and solar zenith angle, are considered [55]. The equations presented by Chander et al. and Mishra et al. [56,57] were used for the radiometric calibration of the satellite images acquired by Landsat 5,7 , and 8 . The data obtained from the USGS website included the highest quality Level-1 Precision Terrain (L1TP) data, which are appropriate for time series analysis. Landsat imagery was geo-referenced with the root mean square error less than a half pixel $[19,58]$. 
Landsat 7 ETM+ has been suffering from an instrument failure since year 2003, and reducing pixel capturing by approximately $22 \%$ per scene [59]. In this study, in order to address the unscanned line issue, the neighborhood similar pixel interpolator (NSPI) method developed by Chen et al. was used to fill the gaps in the SLC-off in Landsat 7 ETM+ images [60]. In order to interpolate the pixel values within unscanned lines, the NSPI method assumed that the same-class neighboring pixels around the un-scanned pixels have similar spectral characteristics, and that these neighboring and un-scanned pixels exhibit similar patterns of spectral differences for each date. It has been documented that the method can restore values of missed pixels very accurately, especially well in heterogeneous regions [60].

\subsubsection{LST and Surface Biophysical Parameters}

LST was calculated from Landsat 5, 7, and 8 by using the single channel (SC) [61,62] algorithm based on Equation (1). Since the thermal band 11 of Landsat 8 has a bias and a large error in calculating the LST [63], band 10 of the Landsat 8 imagery was used to calculate the LST through the SC algorithm.

$$
\mathrm{LST}=\gamma\left[\frac{1}{\varepsilon}\left(\psi_{1} \mathrm{~L}_{\lambda}+\psi_{2}\right)+\psi_{3}\right]+\delta
$$

where LST is the land surface temperature (Kelvin), $\mathrm{L}_{\lambda}$ is the spectral radiance at the sensor in terms of Watts $/\left(\mathrm{m}^{2}\right.$ sr um) in the thermal band, $\varepsilon$ is land surface emissivity (LSE), and $\gamma$ and $\delta$ are two parameters dependent on the Plank function (see [62,64]). The variables of $\psi_{1}, \psi_{2}$, and $\psi_{3}$ are constant atmospheric functions $[61,62]$. The LSE for each date were retrieved by the NDVI threshold method $\left(\mathrm{NDVI}^{\mathrm{THM}}\right)[62,65]$.

In this study, thermal bands of Landsat 5 and 8 were resampled to $30 \mathrm{~m}$ with the cubic method. Then, based on Landsat imagery by combining resampled thermal bands with an LSE with a spatial resolution of $30 \mathrm{~m}$, the LST with a spatial resolution of $30 \mathrm{~m}$ was obtained.

The accuracy of LST values was evaluated using MOD11A1 and soil temperature data recorded by ground-based devices at the moment of the satellite's overpass. The correlation coefficient and root mean square error (RMSE) were calculated between the LST values obtained from the Landsat images and the soil temperature measured at location of the meteorological station. In addition, the values of the correlation coefficient and RMSE were calculated between the mean LST obtained from the Landsat image and MOD11A1 of the case study for the years 2001 to 2018.

To assess the impact of each biophysical parameter changes on the LST variations, various spectral indices were computed to extract the surface biophysical parameters based on Landsat 5, 7, and 8 imagery. In this study, NDVI [66], the soil-adjusted vegetation index (SAVI) [67], normalized difference water index (NDWI) [68], NDBI [69], albedo [70,71], and tasseled cap transformation (TCT) components, including brightness, greenness, and wetness [72-74], were used to represent the surface biophysical parameters (Table 1).

Table 1. Description of surface biophysical parameters.

\begin{tabular}{|c|c|c|}
\hline $\begin{array}{l}\text { Biophysical } \\
\text { Parameter }\end{array}$ & Description & References \\
\hline NDVI & $\frac{\rho_{\text {NIR }}-\rho_{\text {Red }}}{\rho_{\text {NIR }}+\rho_{\text {Red }}}$ & [66] \\
\hline SAVI & $\frac{(1+L)\left(\rho_{\text {NIR }}-\rho_{\text {Red }}\right)}{\rho_{\text {NIR }}+\rho_{\text {Red }}+L}$ & [67] \\
\hline NDWI & $\frac{\rho_{\mathrm{GREEN}}-\rho_{\mathrm{NIR}}}{\rho_{\mathrm{GREEN}}+\rho_{\mathrm{NIR}}}$ & [68] \\
\hline NDBI & $\frac{\rho_{S W I R}-\rho_{N I R}}{\rho_{S W I R}+\rho_{N I R}}$ & [69] \\
\hline Brightness & $\begin{array}{c}0.3029 \text { Blue + 0.2786Green + 0.4733Red + 0.5599NIR + 0.5080SWIR } 1+ \\
\text { (For Landsat 8) } 0.1872 \text { SWIR2 }\end{array}$ & [72-74] \\
\hline
\end{tabular}


Table 1. Cont.

\begin{tabular}{|c|c|c|}
\hline $\begin{array}{l}\text { Biophysical } \\
\text { Parameter }\end{array}$ & Description & References \\
\hline Greenness & $\begin{array}{l}-0.2941 \text { Blue }-0.243 \text { Green }-0.5424 \text { Red }+0.7276 N I R+ \\
\quad \text { (For Landsat 8) 0.0713SWIR } 1-0.1608 \text { SWIR2 }\end{array}$ & \multirow{2}{*}{ [72-74] } \\
\hline Wetness & $\begin{array}{c}0.1511 \text { Blue }+0.1973 \text { Green }+0.3283 R e d+0.3407 N I R-0.7117 \text { SWIR } 1- \\
\text { (For Landsat 8) 0.4559SWIR2 }\end{array}$ & \\
\hline
\end{tabular}

\subsubsection{LST and Surface Biophysical Parameters Variations}

PCA is one of the techniques for determining variations of environmental parameters in the temporal dimension [75-77]. The variations of environmental parameters in the temporal dimension can be examined on a pixel scale using PCA [78-80]. To model the variations of each particular parameter over a given time interval, a PCA model was applied to its specific values over a time scale at the pixel scale. If there are $n$ images during each specific interval, for each pixel, $n$ values of each surface biophysical parameters and LST were modeled. As a result, for modeling the variation of each parameter, the PCA model was implemented on $n$ values of each pixel [79]. The PC1 output can contain both negative and positive values. A higher and more positive value of a pixel in PC1 indicates that the values of this pixel have been large and unchanged over time. In contrast, a lower and more negative value of a pixel in PC1 indicates that the values of that pixel have been low and unchanged over time. A PC1 value close to zero indicates that changes in the values of the pixel have been high over time [78-80].

Due to the limited size and flatness of the study area, we assumed that the impact of the climatic and topographic parameters on LST spatial distribution remained the same and that the spatial variations in LST were mainly associated with the changes in surface biophysical parameters such as brightness, greenness, and wetness of surface. The climate background difference can only affect the absolute LST values but not affect the distribution pattern of the LST in one date. However, it is difficult to compare directly the impact of the surface biophysical parameters on LST due to the climate background difference in the temporal dimension. To solve this problem, a normalization technique was used. Therefore, normalization to the LST and surface biophysical parameters with different climate backgrounds can rescale each parameter to the same level between 0 and 1 and thus reduce the climate background difference $[8,19,81]$. By utilizing minima and maxima for each parameter, all LST and surface biophysical parameters maps were normalized using Equation (2) [81]:

$$
\text { NParameter }_{i}=\frac{\text { Parameter }_{i}-\text { Parameter }_{\text {min }}}{\text { Parameter }_{\max }-\text { Parameter }_{\min }}
$$

where NParameter $r_{i}$ is the normalized LST and surface biophysical parameters of i pixel, Parameter ${ }_{i}$ the LST and surface biophysical parameters of i pixel, Parameter $_{\text {min }}$ the minimum, and Parameter ${ }_{\max }$ the maximum LST and surface biophysical parameters value in each date. In this study, a PCA model was applied on normalized LST and surface biophysical parameters.

On the other hand, PC1 contains the major information of variability in the time series, whereas the other PCs contain the seasonal variability of the time series, each related to a certain parameter or parameters [46-48].

\subsubsection{Impact of Surface Biophysical Parameter Variations on LST Variations}

To investigate the impact of the surface biophysical parameters variations on LST variations in both spatial and temporal dimensions, the combination of PCA [82] and OLS regression [83] was employed. In this step, to analyze the impact of variations in the surface biophysical parameters on the LST variations in the temporal and spatial dimensions in an integrated manner, the relationship between the PC1 of the LST and PC1 of each surface biophysical parameter was examined using the OLS regression with regional and local optimization. The correlation coefficient and RMSE were used 
to determine the amount of the impact. The higher correlation coefficient values and lower RMSE indicate the greater impact of changing a particular parameter on the LST variation. To determine the spatial distribution of the most influential biophysical parameter on the LST variations in the study area, the RMSE value between the observed and modeled LST variations based on each biophysical parameter variations was compared.

\section{Regional and Local Optimization}

In this study, two different approaches of regional and local optimization were applied to solve the regression coefficients of the OLS regression in analyzing the impact of different surface biophysical parameters changes on the LST variations. In the regional optimization, the values of all pixels (the whole region) of the dependent variable (PC1 of LST) and independent variables (PC1s of biophysical parameters) were used in OLS regression. Furthermore, the local optimization approach was utilized for analyzing the impact of different surface biophysical parameters changes on the LST variations. In the local optimization, the regression coefficients of the surface biophysical parameters were calculated for each pixel individually. In order to determine the optimal value of the regression coefficient associated with each biophysical parameter for each pixel, only the values of neighboring pixels in the spatial window were introduced in OLS regression. OLS regression with a moving window provided the optimal values of the regression coefficients on the pixel scale. In this approach we used all the pixels in the window to get the optimal value of the regression coefficient for the center pixel. The conceptual model of regional and local approaches to calculate the optimal values of the regression coefficients is shown in Figure 4.
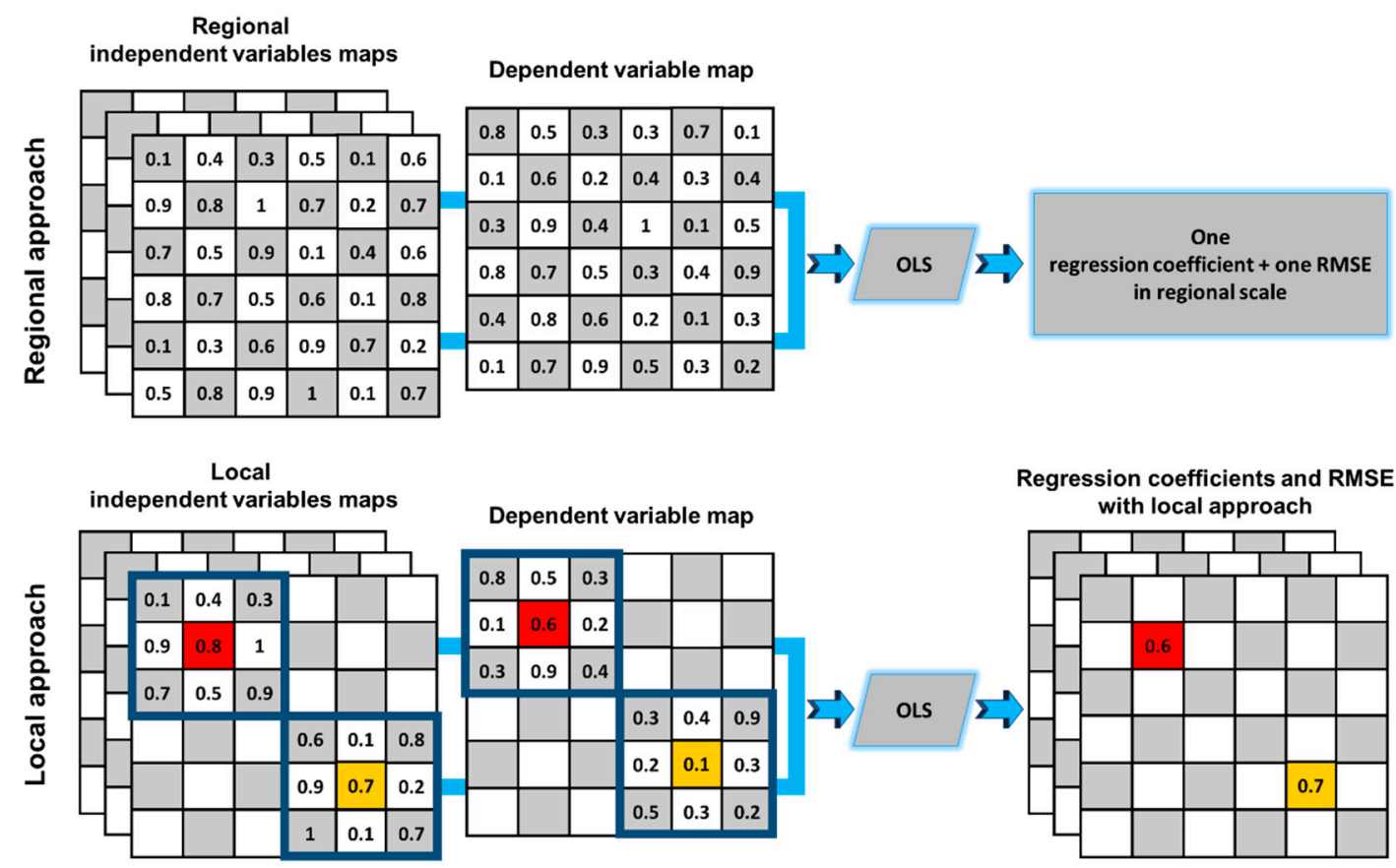

Figure 4. Conceptual model for determining regression coefficients with regional and local optimization.

The moving window size (MWS) is also directly related to the accuracy of LST variation modeling. The criteria for selecting the appropriate MWS according to the homogeneity degree of surface biophysical parameters in study area should be determined. In this study, the semivariance function was used for determining the appropriate MWS. See detail of this function in [84]. The optimal MWS for this study area yielded $21 \times 21$ pixels. 


\subsubsection{Modeled LST Variations Based on Multivariate OLS Regression}

In this study, through the simultaneous consideration of PC1 of the most influential biophysical parameter, the LST variations was modeled. For this purpose, the multivariate OLS regression with both regional and local optimization was employed. In this study, from each group of indices related to impervious surfaces (albedo, NDBI, and brightness obtained from tasseled cap), vegetation covers (NDVI, SAVI, and greenness obtained from Tasseled cap), and wetness surfaces (NDWI and wetness obtained from tasseled cap), one parameter was selected as the most effective parameter for modeling LST variations. Finally, for accuracy assessment, the correlation coefficient and RMSE between the observed and modeled values of LST variations at regional and local optimization were investigated.

\section{Results}

\subsection{LST and Surface Biophysical Parameters}

The correlation coefficient yielded 0.91 between Landsat-derived LST values and soil temperatures measured at the location of the meteorological station. Furthermore, the correlation coefficient between the mean LST obtained from Landsat and that from MOD11A1 reached 0.93. These results indicate that LST calculated with the Landsat images possessed a high accuracy. The RMSE parameter yielded $1.80^{\circ} \mathrm{C}$ between the Landsat LSTs and the soil temperatures, and $1.37^{\circ} \mathrm{C}$ between the mean LST from Landsat images and MOD11A1. According to previous studies $[19,85,86]$, RMSE value of less than $2{ }^{\circ} \mathrm{C}$ between the mean LST obtained from Landsat and MOD11A1 indicates the high accuracy of LST derivation. Examples of the derived LST maps at different days from 1985 to 2018 are shown in Figure 5. The results indicated that LST values increased over the years of studied period.

The mean LST of the region was further investigated from 1985 to 2018 and the results are shown in Figure 6. The result indicates that the mean LST for the study area changed over the time. The maximum of the mean LST in the warm months (May and June) in the late 1980s and early 1990s was around $25^{\circ} \mathrm{C}$, with a significant increase to over $30^{\circ} \mathrm{C}$ after 2010 . Less variations occurred in the minimum of the mean LST in the cold months (approximately $2{ }^{\circ} \mathrm{C}$ ).

The mean normalized values of each surface biophysical parameter during 1985-2018 are shown in Figure 7.

According to Figure 7, the mean normalized values for the surface biophysical parameters varied significantly in the period of 1985-2018. The standard deviation of the mean values of the NDVI, NDBI, NDWI, greenness, wetness, albedo, SAVI, and brightness are $0.0718,0.086,0.074,0.115,0.075,0.1135$, 0.067 , and 0.098 , respectively. The correlation coefficient between the observed mean values of the normalized LST (NLST) and mean normalized values of the surface biophysical parameters are shown in Table 2.

Table 2. Correlation coefficient between the mean values of the NLST and mean normalized values of surface biophysical parameters.

\begin{tabular}{ccccccccc}
\hline $\begin{array}{c}\text { Surface } \\
\text { Biophysical } \\
\text { Parameters }\end{array}$ & NDVI & NDBI & NDWI & Albedo & Greenness & Wetness & Brightness & SAVI \\
\hline R squared & -0.44 & 0.71 & 0.29 & 0.58 & -0.57 & -0.68 & 0.63 & -0.46 \\
$p$-Value & 0.01 & 0.01 & 0.02 & 0.01 & 0.00 & 0.01 & 0.02 & 0.00 \\
\hline
\end{tabular}

The results of the initial investigation indicate that NDWI and NDBI have the lowest and the highest impact on the LST, respectively. The correlation coefficient between the LST and NDBI was high [36]. 


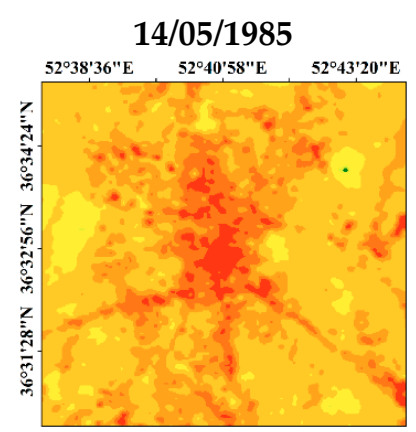

$12 / 08 / 2003$

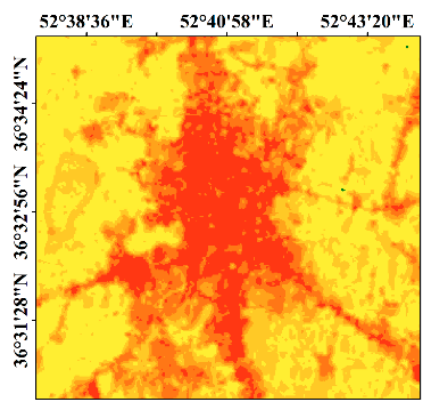

27/03/2011

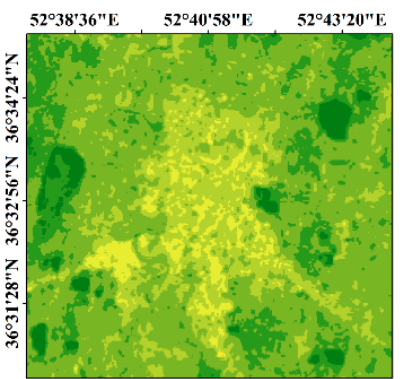

23/08/2016

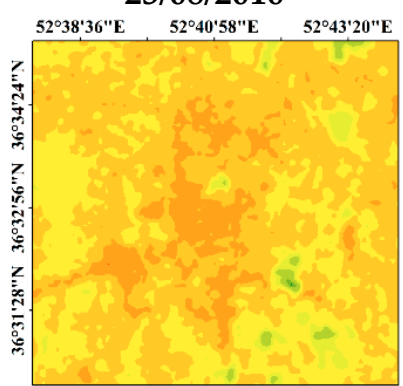

$<16$

16 - 19

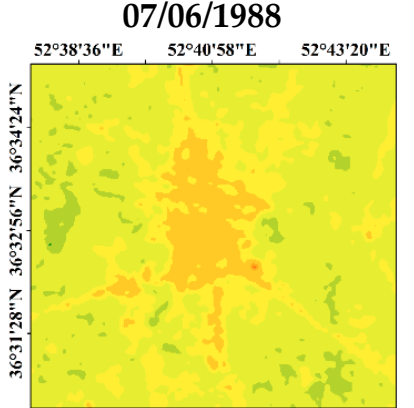

19/05/2007

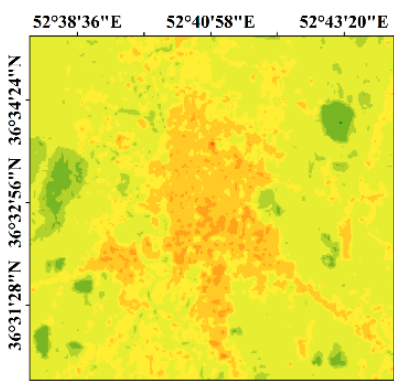

$25 / 07 / 2014$

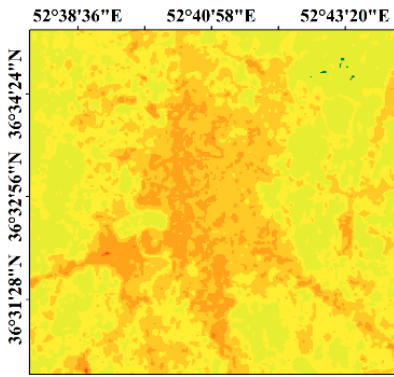

10/08/2017

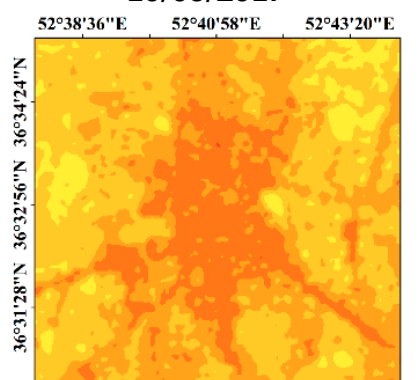

19 - 22

22 - 25
25 - 28

28 - 31

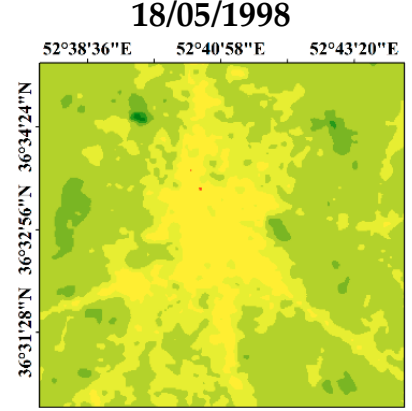

24/11/2009

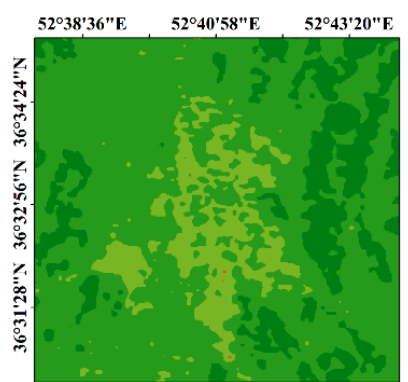

18/06/2015

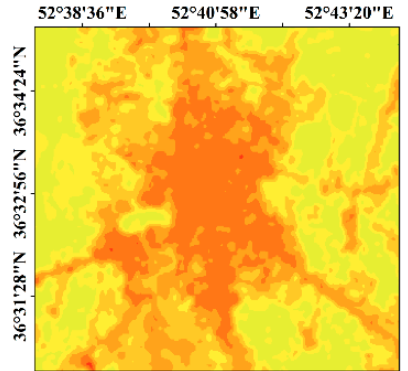

$22 / 03 / 2018$

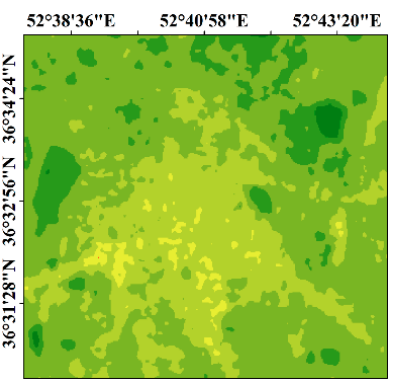

31 - $34 \quad 37-41$

Figure 5. Examples of land surface temperature (LST) maps $\left({ }^{\circ} \mathrm{C}\right)$ for the time period of $1985-2018$ in Babol City, Iran. 


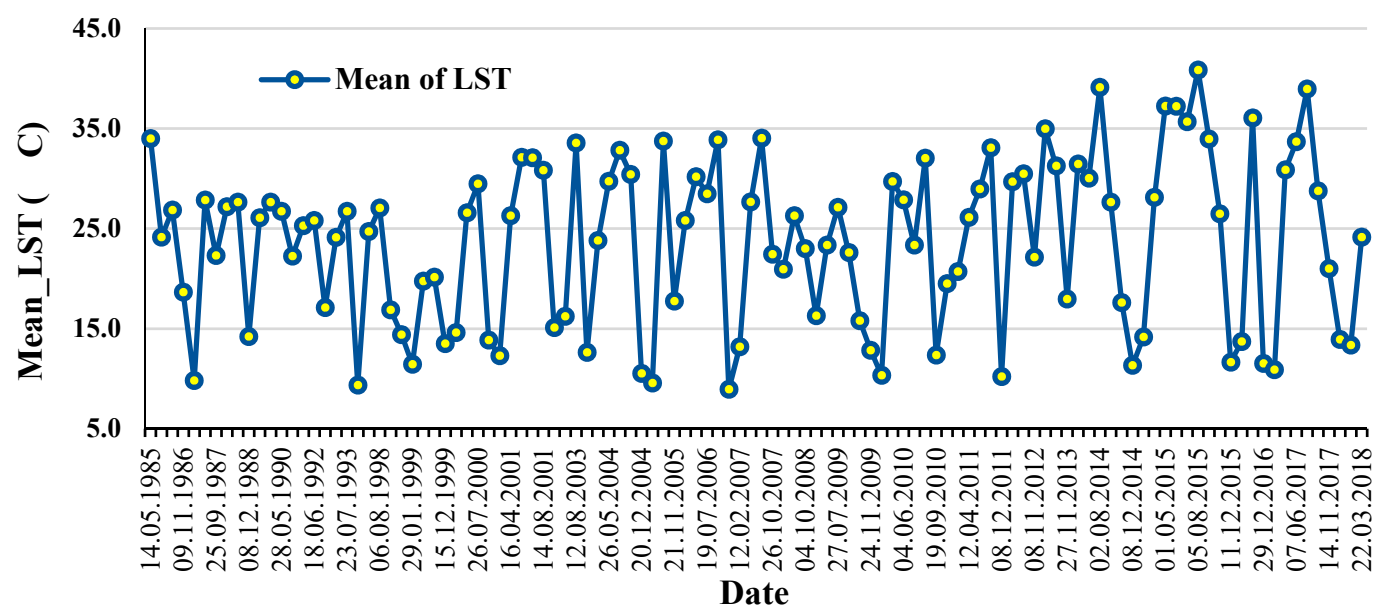

Figure 6. The mean LST in Babol, Iran, from 1985 to $2018\left({ }^{\circ} \mathrm{C}\right)$.
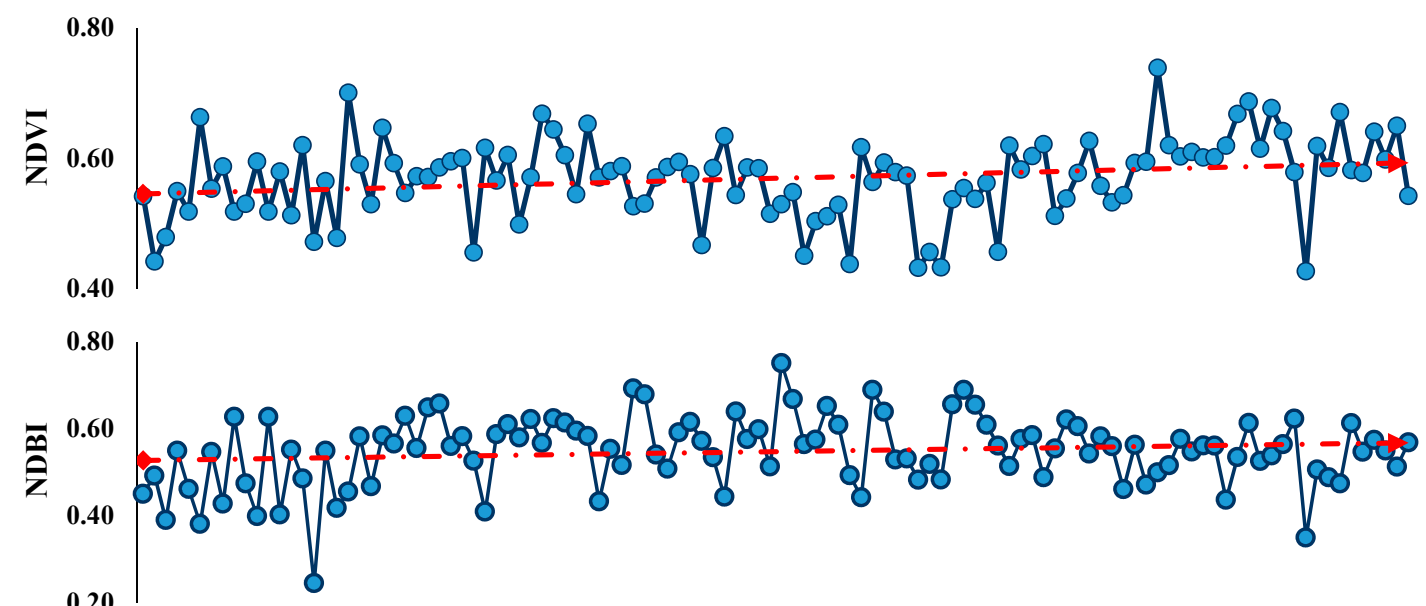

0.60
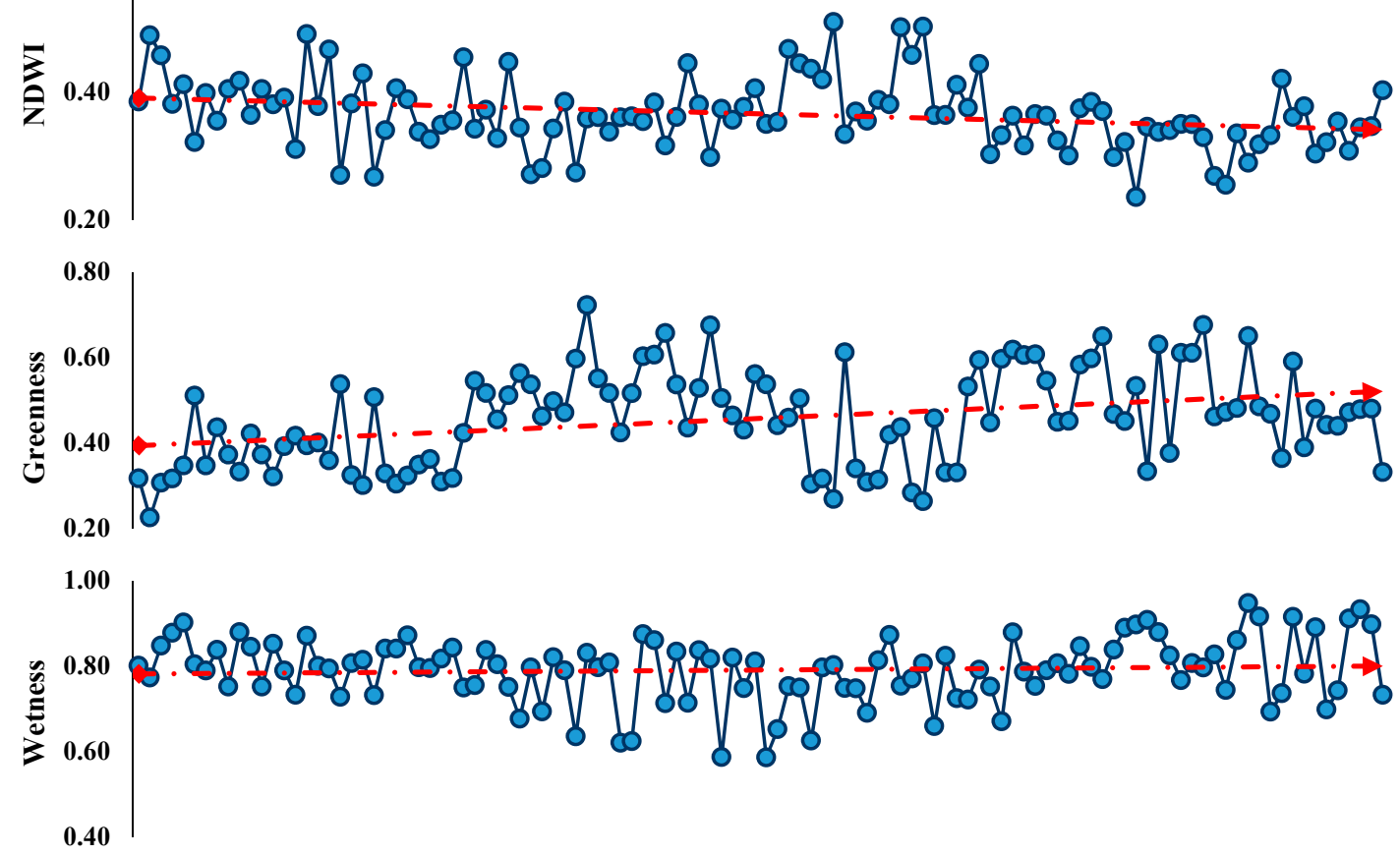

Figure 7. Cont. 

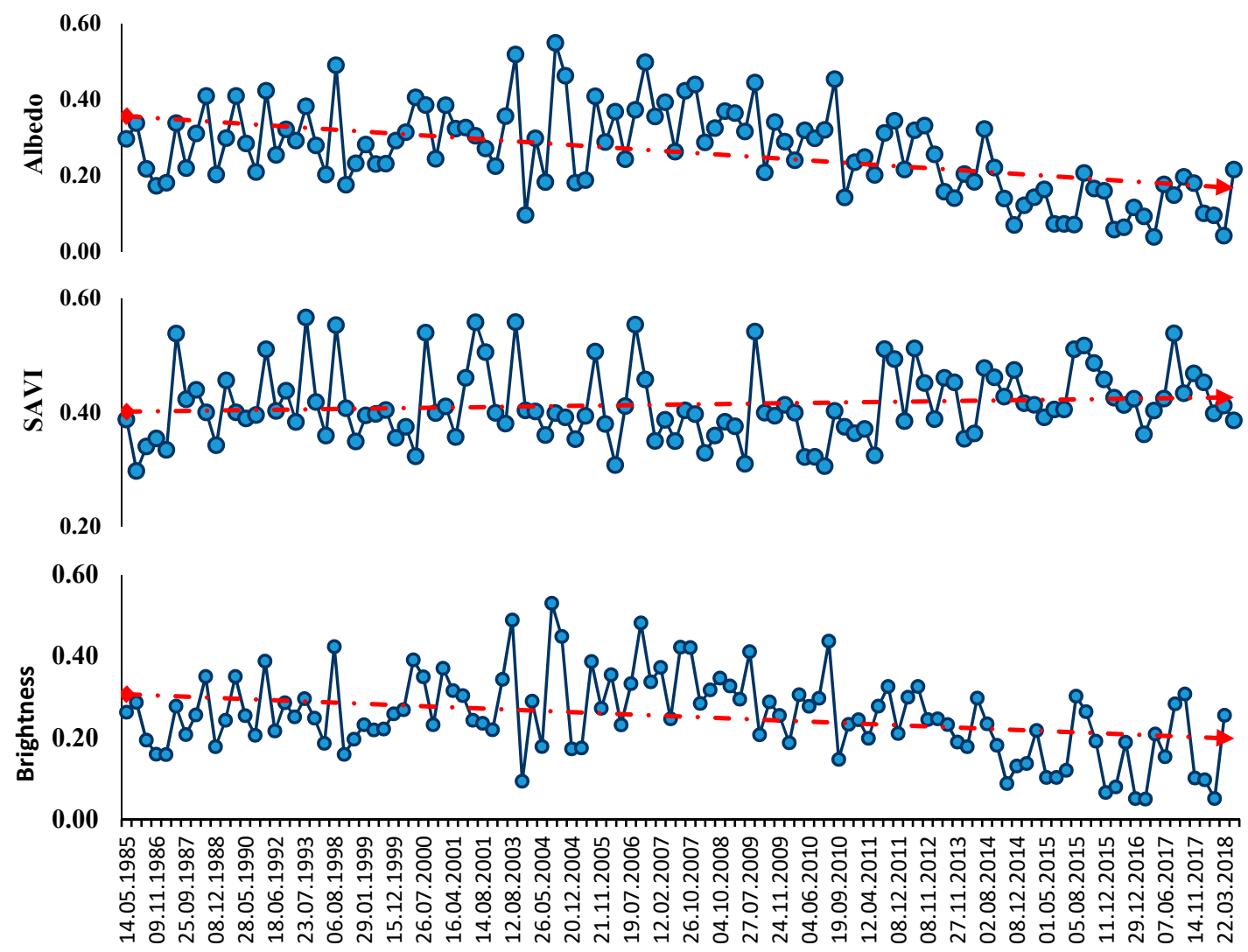

Figure 7. The mean normalized values of each surface biophysical parameter.

\subsection{LST and Surface Biophysical Parameters Variations}

The PC1 maps for the LST and other surface biophysical parameters are shown in Figure 8. A higher and more positive value of a pixel in PC1 indicates that the values of this pixel have been large and unchanged over time (red regions in Figure 8). In contrast, a lower and more negative value of a pixel in PC1 indicates that the values of that pixel have been low and unchanged over time (blue regions in Figure 8). A PC1 value close to zero indicates that changes in the values of pixels have been high over time.

Based on Figure 8, the pixels that had been built-up lands in most of the dates had the highest values of LST, NDBI, albedo, and brightness and, therefore, the highest PC1s of LST, NDBI, albedo, and brightness values. This is in contrast to those pixels that had low values of NDVI, SAVI, and greenness, and thus lower values of the PCIs for these surface parameters. The pixels that changed from green space and agriculture lands to built-up land, had PC1 values of LST and surface biophysical parameters close to zero.

\subsection{Impact of Surface Biophysical Parameters Variations on LST Variations}

\subsubsection{Regional Optimization}

The results of the relationship between the PC1 of LST and the PC1 of each surface biophysical parameters based on OLS regression with regional optimization are presented in Figure 9.

Figure 9 indicates that among the spectral indices considered, the variations in the greenness from TCT components (from group of biophysical parameters related to vegetation covers), NDBI (from group of biophysical parameters related to impervious surfaces), and wetness from TCT components (from group of biophysical parameters related to wetness surfaces) have the highest impact on the LST variations, respectively. Based on regional optimization, among the various surface biophysical parameters, NDBI variations had the highest impact on the LST variations. The results of the initial 
investigation indicate that in this study area, variations of NDWI and NDBI have the lowest and the highest impact on the LST variations, respectively (Figure 9). The correlation coefficient between the LST and NDBI was high [36].
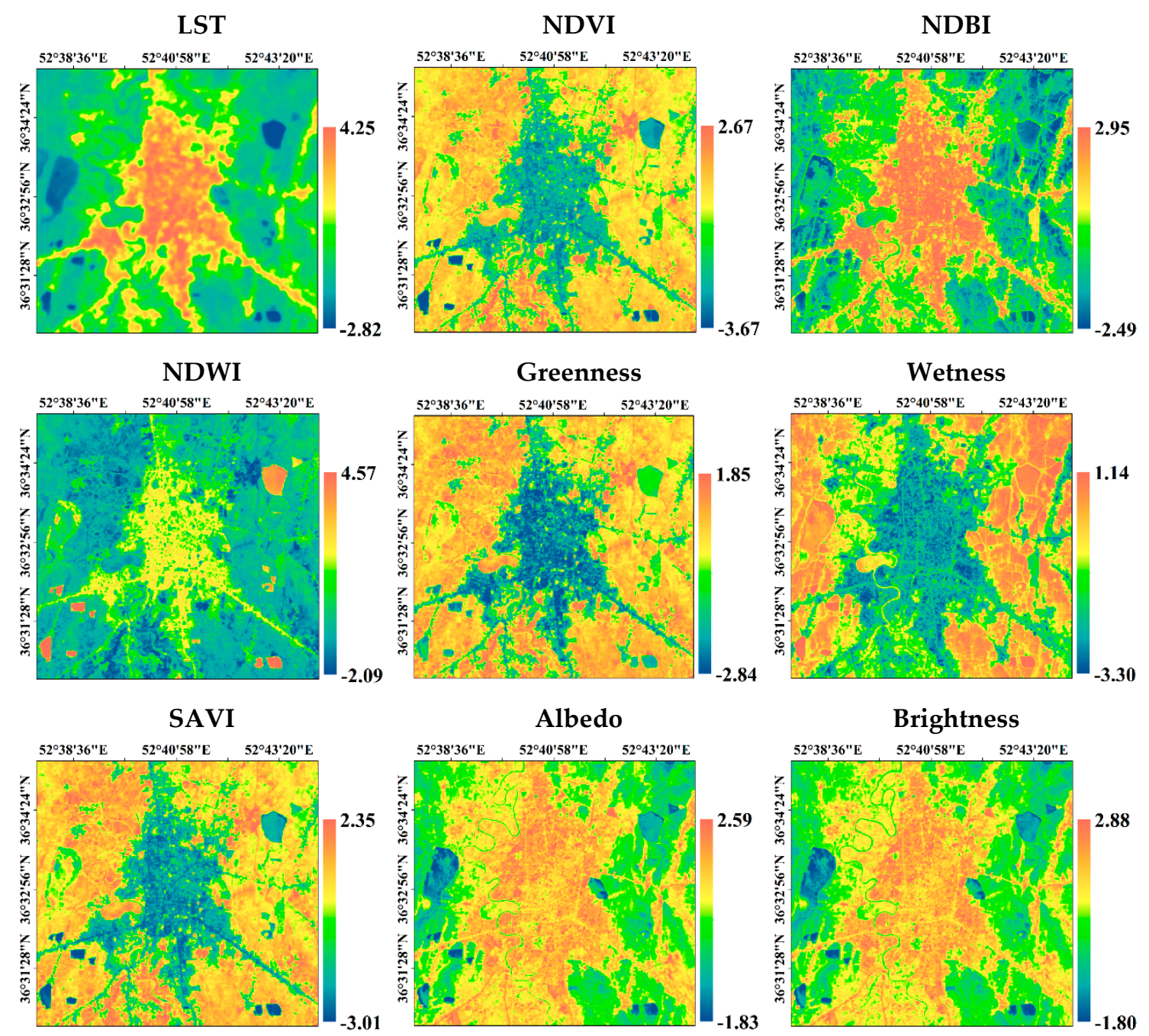

Figure 8. PC1 maps of LST and various surface biophysical parameters.

\subsubsection{Local Optimization}

The results of the correlation coefficient and RMSE between the observed and modeled values of the LST variations based on the spatial moving window method are shown in Figure 10 and Table 3. The results indicated the values of the correlation coefficient and RMSE between the observed and modeled values of LST variations are variable spatially.

Table 3. Mean and standard deviation of the correlation coefficient and RMSE between the observed and modeled values of the LST variations at the pixel scale based on the variations of each surface biophysical parameters.

\begin{tabular}{ccccccccc}
\hline $\begin{array}{c}\text { Surface Biophysical } \\
\text { Parameters }\end{array}$ & NDVI & NDBI & NDWI & Albedo & Greenness & Wetness & Brightness & SAVI \\
\hline Mean value of R & -0.37 & 0.75 & 0.29 & 0.59 & -0.44 & -0.70 & 0.65 & -0.37 \\
$\quad$ Std of R & 0.50 & 0.22 & 0.54 & 0.30 & 0.48 & 0.25 & 0.26 & 0.30 \\
Mean value of RMSE & 1.15 & 0.71 & 1.17 & 1.05 & 1.06 & 1.03 & 1.05 & 1.15 \\
$\quad$ Std of RMSE & 0.95 & 0.32 & 0.95 & 0.48 & 0.77 & 0.87 & 0.49 & 0.91 \\
\hline
\end{tabular}


The results of Table 3 indicate that among the spectral indices considered for the surface biophysical parameters of the vegetation cover, impervious surface cover, and wetness surface cover, the variation in the greenness (from the group of biophysical parameters related to vegetation covers), NDBI (from the group of biophysical parameters related to impervious surfaces), and wetness (from the group of biophysical parameters related to wetness surfaces) have the highest effect on the LST variations, respectively. Based on the RMSE between the observed and modeled values of LST variations at the pixel scale for greenness, NDBI, and wetness variations (Figure 10), the results of the spatial distribution of the most effective biophysical parameter variations on LST variations are shown in Figure 11.
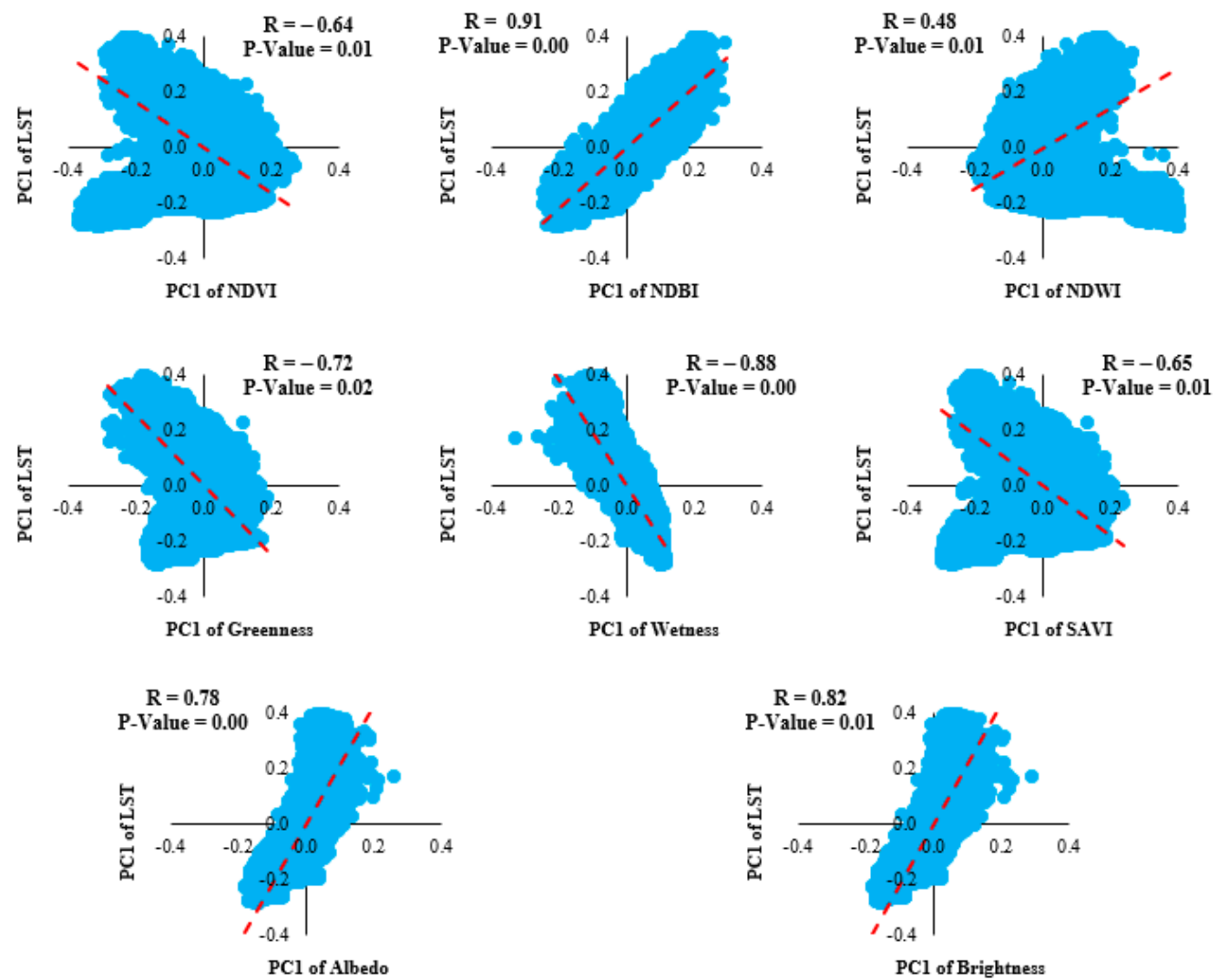

Figure 9. Relationship between the PC1 of LST and the PC1 of each surface biophysical parameters using OLS regression with a regional approach.

The results show that variations of NDBI, wetness, and greenness from TCT were the most influential parameters on LST variations, accounting for $43 \%, 38 \%$, and $19 \%$ of the LST variations, respectively. The greenness variation had a lower impact on the LST variations than NDBI and wetness.

\subsection{Modeled LST Variations Based on Multivariate OLS Regression}

Modeled LST variations based on NDBI, greenness, and wetness variations using multivariate OLS regression with regional and local optimizations are shown in Figure 12. 

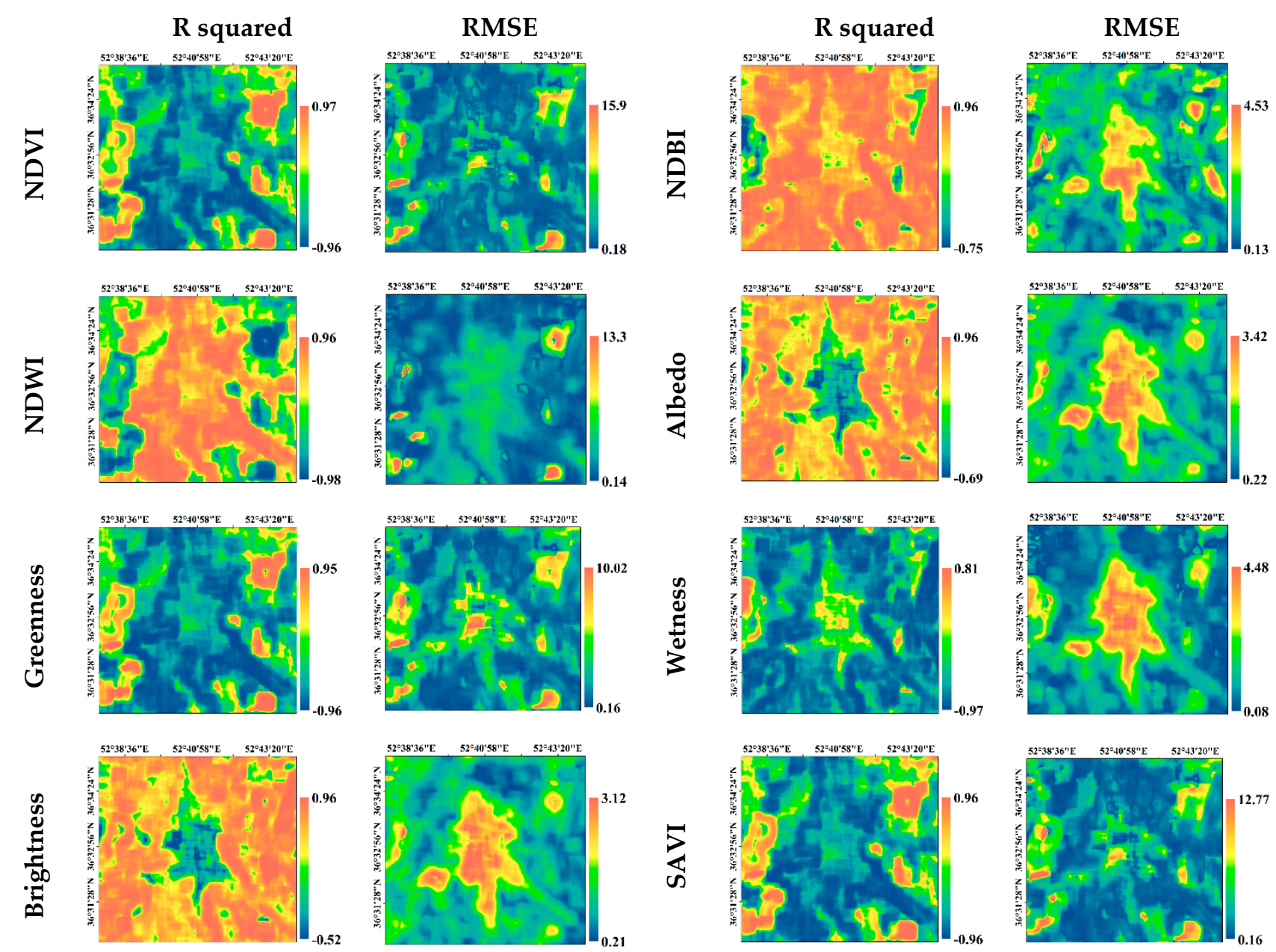

Figure 10. Correlation coefficient and RMSE between the observed and modeled values of LST variations at the pixel scale based on each surface biophysical parameter variations. 


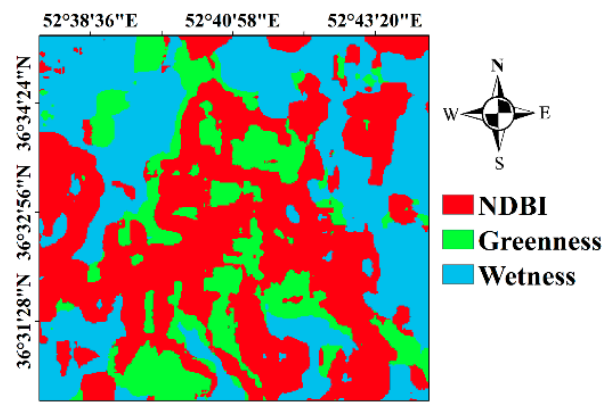

Figure 11. Spatial distribution of the most influential biophysical parameters on LST variations.
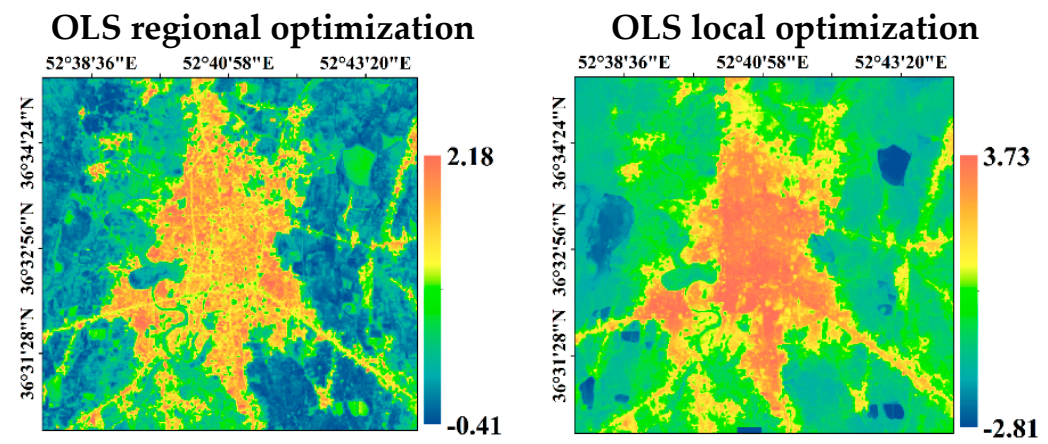

Figure 12. Modeled LST variations based on NDBI, greenness, and wetness variations using multivariate OLS regression with regional and local optimizations $\left({ }^{\circ} \mathrm{C}\right)$.

The mean of the PC1 of LST, modeled LST variations based on NDBI, greenness, and wetness variations using multivariate OLS regression with regional and local approaches are $0.00,-0.12$, and 0.04 , respectively. The correlation coefficient and RMSE between the surface biophysical parameters (NDBI, greenness, and wetness) variations and the LST variations based on the local approaches are shown in Figure 13, respectively. The assessment of the relationship between the surface biophysical parameters (including the NDBI, greenness, and wetness) variations and the LST variations indicates that the correlation coefficient values for regional and local optimization are 0.85 and 0.93 , respectively, while the RMSE values for regional and local optimization are 1.06 and 0.26 , respectively. The results demonstrate that LST variations can be modeled with a reasonably high accuracy based on the surface biophysical parameters variations such as the NDBI, greenness, and wetness.

\section{$R$, local optimization}

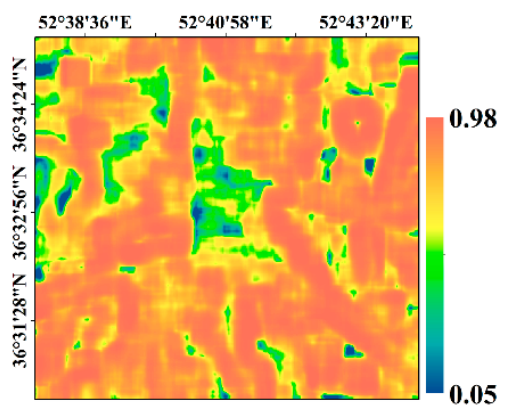

\section{RMSE, local optimization}

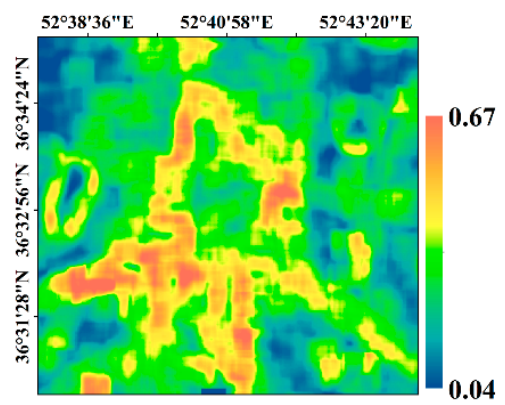

Figure 13. The correlation coefficient and RMSE between the surface biophysical parameters variations and the LST variations based on the local approach.

\section{Discussion}

In this study, to investigate the impact of surface biophysical parameters variations on LST variations, a spatial moving window method using the OLS regression with both regional and local 
optimization was applied. It should be noted when the OLS regression was applied some challenges must be considered, such as the initial assumption of normal distribution input data, the requirement of enough samples, and the existence of outlier values in data.

The results of this study demonstrate that the spatial distribution of LST values varied during different times. A visual examination of LST maps in Figure 5 shows that LST of built-up lands was higher than that of non-built-up lands, due to the replacement of agricultural lands and green spaces by built-ups around Babol City [8]. The impact of the physical expansion of the city on the spatial distribution of LST values was recognizable for the study area. According to Firozjaei et al. the maximum temperature changes in the study area were found at a distance of 0-800 $\mathrm{m}$ from built-up land areas due to the transformation of agricultural land and green space into built-up land. An increase in distance from built-up land brought about a decrease in land uses changes, and the surface temperature changes also diminished [8].

In general, the value of LST decreases with increasing surface brightness (NDBI, albedo, and brightness from TCT components) and reduced vegetation (NDVI, SAVI, and greenness from TCT components) and the moisture (NDWI and wetness from TCT components) on the surface, and vice versa $[16,33,87]$. A negative relationship was found between vegetation and moisture indices and LST, which was most likely due to the effect of surface thermal inertia and evapotranspiration $[3,36]$. However, according to Figure 10, there was a direct relationship between the LST variations and greenness variations in some regions. According to previous studies, there is an inverse relationship between the LST variations and the vegetation variations [7,33]. In areas where there is a positive relationship between the LST variations and the vegetation variations, this may be due to the high impact of other surface biophysical parameters variations on the LST variations. In addition, the relationship between the LST variations and NDBI variations is supposed to be direct [23]. However, according to Figure 10, the relationship between these two parameters is negative in some region of the case study; this is indicative of the higher impact of some other surface biophysical parameters, such as greenness and wetness, on the LST variations in these regions. For this reason, simultaneous investigation of the relationship between the variations in surface biophysical parameters variations and LST variations is compelling [3,13,32]. Using multivariate OLS regression, it is possible to consider the influence of several independent parameters on a dependent parameter. In the present study, through the simultaneous consideration of the PC1 of the three surface biophysical parameters (NDBI, greenness, and wetness) and the PC1 of the LST, the impact of a set of surface biophysical parameters on LST variation was investigated (Figures 12 and 13).

In recent studies, various models have been applied to investigate the impact of biophysical parameters on LST [3,13,14,32,88]. These studies often used regression models with a regional optimization, which is considered a major limitation. This study assessed LST and biophysical parameters variations in the temporal dimension at the pixel scale with PCA, which is straightforward. Moreover, to investigate the impact of surface biophysical parameters variations on LST variations, a local optimization was applied. Using the spatial moving window, the possibility of examining the relationship between the PC1 of LST and the PC1 of each surface biophysical parameter has been provided in the pixel scale with respect to the neighboring pixels. The results of study indicate that the efficiency of the PCA-OLS with the local optimization was higher than the one with the regional optimization.

Generally, the heterogeneous spatiotemporal distribution of surface biophysical parameters such as brightness, greenness, and wetness of the region can cause the heterogeneous distribution of LST [32,33]. Studies on the spatial and temporal variations of LST in regions with heterogeneous topography, the impacts of climatic conditions, and topographic effect such as lapse rate and downward radiation to the surface should further be considered $[2,14]$. He et al. indicated there was a complex relationship between the terrain factors and LST over mountainous regions [31]. For this reason, the downward radiation to the surface should be calculated on a pixel scale [14]. The downward radiation to the surface depends on a set of factors such as the amount of cloudy sky, atmospheric conditions, 
time of day and year, latitude and longitude, albedo, as well as the topographical conditions of the surface and the neighborhood's surface $[87,89,90]$.

\section{Conclusions}

The issue of LST variations is among the most significant factors on various environmental applications. In this study, two models of PCA and OLS regression with regional and local optimization were employed to assess the variations of LST and surface biophysical parameters in the temporal dimension at the pixel scale and to investigate the impact of surface biophysical parameters on LST variations. The variations of environmental parameters in the temporal dimension can be examined on a pixel scale using PCA. The results indicate that among the surface biophysical parameters, the variations of greenness from TCT components, NDBI, and wetness from TCT components had the highest impact on LST variations. The effective surface biophysical parameters on LST variations varied spatially, which can be examined by using an integrated PCA-OLS model. However, the PCA-OLS with local optimization revealed a greater volume of useful information about the impact of surface biophysical variations on LST variations in the temporal and spatial dimensions. It is suggested that future studies should explore the usage of random forest regression to investigate the impact of surface biophysical variations on LST variations in complex regions because random forest is a flexible machine-learning algorithm that could produce good results without hyper-parameter tuning, and is easy to measure the relative importance of each feature on the prediction $[3,29,32,91-93]$. But, the complexity and required time for impediment with RF regression is higher relative to OLS regression [94]. It is suggested to use RF regression to model LST variations in complex regions due to the need to consider more effective parameters.

Author Contributions: M.K.F., A.S., N.M., M.K., and S.K.A. conceived and designed the research of the first draft; M.K.F., A.S., and N.M. performed data analysis and wrote the first draft; M.K. and S.K.A. edited the pre-draft; Q.W. and H.L. re-designed the research, revised and edited the paper; all authors contributed to and approved the final manuscript.

Funding: This research received no external funding

Acknowledgments: We are grateful to editor and four anonymous reviewers for their valuable comments and suggestions to improve this study. In addition, the authors deeply thank the Iran National Science Foundation (INSF) and International Relationship Program, University of Tehran for its great support in conducting this research.

Conflicts of Interest: The authors declare no conflict of interest.

\section{References}

1. Anderson, M.; Norman, J.; Kustas, W.; Houborg, R.; Starks, P.; Agam, N. A thermal-based remote sensing technique for routine mapping of land-surface carbon, water and energy fluxes from field to regional scales. Remote Sens. Environ. 2008, 112, 4227-4241. [CrossRef]

2. Weng, Q.; Firozjaei, M.K.; Kiavarz, M.; Alavipanah, S.K.; Hamzeh, S. Normalizing land surface temperature for environmental parameters in mountainous and urban areas of a cold semi-arid climate. Sci. Total Environ. 2019, 650, 515-529. [CrossRef] [PubMed]

3. Zhao, W.; Duan, S.-B.; Li, A.; Yin, G. A practical method for reducing terrain effect on land surface temperature using random forest regression. Remote Sens. Environ. 2019, 221, 635-649. [CrossRef]

4. Long, D.; Singh, V.P. A two-source trapezoid model for evapotranspiration (ttme) from satellite imagery. Remote Sens. Environ. 2012, 121, 370-388. [CrossRef]

5. Jiang, Y.; Weng, Q. Estimation of hourly and daily evapotranspiration and soil moisture using downscaled lst over various urban surfaces. GISci. Remote Sens. 2017, 54, 95-117. [CrossRef]

6. Weng, Q. Thermal infrared remote sensing for urban climate and environmental studies: Methods, applications, and trends. ISPRS J. Photogramm. Remote Sens. 2009, 64, 335-344. [CrossRef]

7. Weng, Q.; Lu, D.; Schubring, J. Estimation of land surface temperature-Vegetation abundance relationship for urban heat island studies. Remote Sens. Environ. 2004, 89, 467-483. [CrossRef] 
8. Firozjaei, M.K.; Kiavarz, M.; Alavipanah, S.K.; Lakes, T.; Qureshi, S. Monitoring and forecasting heat island intensity through multi-temporal image analysis and cellular automata-markov chain modelling: A case of babol city, iran. Ecol. Indic. 2018, 91, 155-170. [CrossRef]

9. Leng, P.; Song, X.; Duan, S.-B.; Li, Z.-L. A practical algorithm for estimating surface soil moisture using combined optical and thermal infrared data. Int. J. Appl. Earth Obs. 2016, 52, 338-348. [CrossRef]

10. Vlassova, L.; Pérez-Cabello, F.; Mimbrero, M.R.; Llovería, R.M.; García-Martín, A. Analysis of the relationship between land surface temperature and wildfire severity in a series of landsat images. Remote Sens. 2014, 6, 6136-6162. [CrossRef]

11. Zhou, X.; Wang, Y.C. Dynamics of land surface temperature in response to land-use/cover change. Geogr. Res. 2011, 49, 23-36. [CrossRef]

12. Guo, G.; Wu, Z.; Xiao, R.; Chen, Y.; Liu, X.; Zhang, X. Impacts of urban biophysical composition on land surface temperature in urban heat island clusters. Landsc. Urban Plan. 2015, 135, 1-10. [CrossRef]

13. Ghosh, A.; Joshi, P. Hyperspectral imagery for disaggregation of land surface temperature with selected regression algorithms over different land use land cover scenes. ISPRS J. Photogramm. Remote Sens. 2014, 96, 76-93. [CrossRef]

14. Malbéteau, Y.; Merlin, O.; Gascoin, S.; Gastellu, J.-P.; Mattar, C.; Olivera-Guerra, L.; Khabba, S.; Jarlan, L. Normalizing land surface temperature data for elevation and illumination effects in mountainous areas: A case study using aster data over a steep-sided valley in morocco. Remote Sens. Environ. 2017, 189, 25-39. [CrossRef]

15. Jiang, J.; Tian, G. Analysis of the impact of land use/land cover change on land surface temperature with remote sensing. Procedia Environ. Sci. 2010, 2, 571-575. [CrossRef]

16. Choudhury, D.; Das, K.; Das, A. Assessment of land use land cover changes and its impact on variations of land surface temperature in asansol-durgapur development region. Egypt. J. Remote Sens. Space Sci. 2019, 22, 203-218. [CrossRef]

17. Son, N.; Chen, C.; Chen, C.; Chang, L.; Minh, V. Monitoring agricultural drought in the lower mekong basin using modis ndvi and land surface temperature data. Int. J. Appl. Earth Obs. 2012, 18, 417-427. [CrossRef]

18. Xie, S.-P.; Deser, C.; Vecchi, G.A.; Ma, J.; Teng, H.; Wittenberg, A.T. Global warming pattern formation: Sea surface temperature and rainfall. J. Clim. 2010, 23, 966-986. [CrossRef]

19. Weng, Q.; Firozjaei, M.K.; Sedighi, A.; Kiavarz, M.; Alavipanah, S.K. Statistical analysis of surface urban heat island intensity variations: A case study of babol city, iran. GISci. Remote Sens. 2019, 56, 576-604. [CrossRef]

20. Giridharan, R.; Emmanuel, R. The impact of urban compactness, comfort strategies and energy consumption on tropical urban heat island intensity: A review. Sustain. Cities Soc. 2018, 40, 677-687. [CrossRef]

21. Van Hove, L.; Jacobs, C.; Heusinkveld, B.; Elbers, J.; Van Driel, B.; Holtslag, A. Temporal and spatial variability of urban heat island and thermal comfort within the rotterdam agglomeration. Build. Environ. 2015, 83, 91-103. [CrossRef]

22. Xiao, H.; Weng, Q. The impact of land use and land cover changes on land surface temperature in a karst area of china. J. Environ. Manag. 2007, 85, 245-257. [CrossRef] [PubMed]

23. Li, H.; Liu, Q.-H.; Zou, J. Relationships of LST to NDBI and NDVI in changsha-zhuzhou-xiangtan area based on MODIS data. Sci. Geogr. Sin. 2009, 2, 018.

24. Zakšek, K.; Oštir, K. Downscaling land surface temperature for urban heat island diurnal cycle analysis. Remote Sens. Environ. 2012, 117, 114-124. [CrossRef]

25. Keramitsoglou, I.; Kiranoudis, C.T.; Weng, Q. Downscaling geostationary land surface temperature imagery for urban analysis. IEEE Geosci. Remote Sens. Lett. 2013, 10, 1253-1257. [CrossRef]

26. Maeda, E.E. Downscaling modis lst in the east african mountains using elevation gradient and land-cover information. Int. J. Remote Sens. 2014, 35, 3094-3108. [CrossRef]

27. Bisquert, M.; Sánchez, J.M.; Caselles, V. Evaluation of disaggregation methods for downscaling modis land surface temperature to landsat spatial resolution in barrax test site. IEEE J. Sel. Top. Appl. Earth Obs. Remote Sens. 2016, 9, 1430-1438. [CrossRef]

28. Zhan, W.; Chen, Y.; Zhou, J.; Wang, J.; Liu, W.; Voogt, J.; Zhu, X.; Quan, J.; Li, J. Disaggregation of remotely sensed land surface temperature: Literature survey, taxonomy, issues, and caveats. Remote Sens. Environ. 2013, 131, 119-139. [CrossRef]

29. Hutengs, C.; Vohland, M. Downscaling land surface temperatures at regional scales with random forest regression. Remote Sens. Environ. 2016, 178, 127-141. [CrossRef] 
30. Sismanidis, P.; Keramitsoglou, I.; Bechtel, B.; Kiranoudis, C. Improving the downscaling of diurnal land surface temperatures using the annual cycle parameters as disaggregation kernels. Remote Sens. 2016, 9, 23. [CrossRef]

31. He, J.; Zhao, W.; Li, A.; Wen, F.; Yu, D. The impact of the terrain effect on land surface temperature variation based on landsat-8 observations in mountainous areas. Int. J. Remote Sens. 2018, 40, 1808-1827. [CrossRef]

32. Yang, Y.; Cao, C.; Pan, X.; Li, X.; Zhu, X. Downscaling land surface temperature in an arid area by using multiple remote sensing indices with random forest regression. Remote Sens. 2017, 9, 789. [CrossRef]

33. Sattari, F.; Hashim, M.; Pour, A.B. Thermal sharpening of land surface temperature maps based on the impervious surface index with the tsharp method to aster satellite data: A case study from the metropolitan kuala lumpur, malaysia. Measurement 2018, 125, 262-278. [CrossRef]

34. Jeganathan, C.; Hamm, N.; Mukherjee, S.; Atkinson, P.M.; Raju, P.; Dadhwal, V. Evaluating a thermal image sharpening model over a mixed agricultural landscape in india. Int. J. Appl. Earth Obs. 2011, 13, 178-191. [CrossRef]

35. Gao, F.; Kustas, W.; Anderson, M. A data mining approach for sharpening thermal satellite imagery over land. Remote Sens. 2012, 4, 3287-3319. [CrossRef]

36. Wang, F.; Qin, Z.; Li, W.; Song, C.; Karnieli, A.; Zhao, S. An efficient approach for pixel decomposition to increase the spatial resolution of land surface temperature images from modis thermal infrared band data. Sensors 2015, 15, 304-330. [CrossRef]

37. Eklundh, L.; Singh, A. A comparative analysis of standardised and unstandardised principal components analysis in remote sensing. Int. J. Remote Sens. 1993, 14, 1359-1370. [CrossRef]

38. Henebry, G.M.; Rieck, D.R. Applying principal components analysis to image time series: Effects on scene segmentation and spatial structure. In Proceedings of the IGARSS'96. 1996 International Geoscience and Remote Sensing Symposium, Lincoln, NE, USA, 31-31 May 1996; pp. 448-450.

39. Singh, A.; Harrison, A. Standardized principal components. Int. J. Remote Sens. 1985, 6, 883-896. [CrossRef]

40. Jensen, J.R. Introductory Digital Image Processing: A Remote Sensing Perspective; Prentice Hall Press: Upper Saddle River, NJ, USA, 2015.

41. Jolliffe, I.T.; Cadima, J. Principal component analysis: A review and recent developments. Philos. Trans. R. Soc. A Math. Phys. Eng. Sci. 2016, 374, 20150202. [CrossRef]

42. Deng, J.; Huang, Y.; Chen, B.; Tong, C.; Liu, P.; Wang, H.; Hong, Y. A methodology to monitor urban expansion and green space change using a time series ofmulti-sensor spot and sentinel-2a images. Remote Sens. 2019, 11, 1230. [CrossRef]

43. Eastman, J.R.; Fulk, M. Long sequence time series evaluation using standardized principal components. Photogramm. Eng. Remote Sens. 1993, 59, 1307-1312.

44. Hall-Beyer, M. Comparison of single-year and multiyear ndvi time series principal components in cold temperate biomes. IEEE Trans. Geosci. Remote Sens. 2003, 41, 2568-2574. [CrossRef]

45. Bellón, B.; Bégué, A.; Lo Seen, D.; de Almeida, C.; Simões, M. A remote sensing approach for regional-scale mapping of agricultural land-use systems based on ndvi time series. Remote Sens. 2017, 9, 600. [CrossRef]

46. Hirosawa, Y.; Marsh, S.E.; Kliman, D.H. Application of standardized principal component analysis to land-cover characterization using multitemporal avhrr data. Remote Sens. Environ. 1996, 58, 267-281. [CrossRef]

47. Wang, T.; Kou, X.; Xiong, Y.; Mou, P.; Wu, J.; Ge, J. Temporal and spatial patterns of ndvi and their relationship to precipitation in the loess plateau of china. Int. J. Remote Sens. 2010, 31, 1943-1958. [CrossRef]

48. De Almeida, T.I.R.; Penatti, N.C.; Ferreira, L.G.; Arantes, A.E.; do Amaral, C.H. Principal component analysis applied to a time series of modis images: The spatio-temporal variability of the pantanal wetland, brazil. Wetl. Ecol. Manag. 2015, 23, 737-748. [CrossRef]

49. Deng, J.; Wang, K.; Deng, Y.; Qi, G. Pca-based land-use change detection and analysis using multitemporal and multisensor satellite data. Int. J. Remote Sens. 2008, 29, 4823-4838. [CrossRef]

50. Panah, S.; Mogaddam, M.K.; Firozjaei, M.K. Monitoring spatiotemporal changes of heat island in babol city due to land use changes. Int. Arch. Photogramm. Remote Sens. Spat. Inf. Sci. 2017, 42, 17-22. [CrossRef]

51. Firozjaei, M.K.; Sedighi, A.; Argany, M.; Jelokhani-Niaraki, M.; Arsanjani, J.J. A geographical direction-based approach for capturing the local variation of urban expansion in the application of CA-Markov model. Cities 2019, 93, 120-135. [CrossRef] 
52. USGS. United States Geological Survey. Available online: https://earthexplorer.usgs.gov/ (accessed on 1 June 2018).

53. LAADS DAAC. Level-1 and Atmosphere Archive and Distribution System Distributed Active Archive Center. Available online: https://ladsweb.nascom.nasa.gov (accessed on 1 June 2018).

54. Mazandaran Meteorological Organization. Available online: http://www.Mazmet.Ir/en (accessed on 1 June 2018).

55. Berk, A.; Conforti, P.; Kennett, R.; Perkins, T.; Hawes, F.; van den Bosch, J. Modtran ${ }^{\circledR}$ 6: A major upgrade of the modtran ${ }^{\circledR}$ radiative transfer code. In Proceedings of the 2014 6th Workshop on Hyperspectral Image and Signal Processing: Evolution in Remote Sensing (WHISPERS), Lausanne, Switzerland, 24-27 June 2014; pp. 1-4.

56. Chander, G.; Markham, B.L.; Helder, D.L. Summary of current radiometric calibration coefficients for landsat mss, tm, etm+, and eo-1 ali sensors. Remote Sens. Environ. 2009, 113, 893-903. [CrossRef]

57. Mishra, N.; Haque, M.O.; Leigh, L.; Aaron, D.; Helder, D.; Markham, B. Radiometric cross calibration of landsat 8 operational land imager (oli) and landsat 7 enhanced thematic mapper plus (etm+). Remote Sens. 2014, 6, 12619-12638. [CrossRef]

58. Moghaddam, M.H.R.; Sedighi, A.; Fasihi, S.; Firozjaei, M.K. Effect of environmental policies in combating aeolian desertification over sejzy plain of iran. Aeolian Res. 2018, 35, 19-28. [CrossRef]

59. Arvidson, T.; Goward, S.; Gasch, J.; Williams, D. Landsat-7 long-term acquisition plan. Photogramm. Eng. Remote Sens. 2006, 72, 1137-1146. [CrossRef]

60. Chen, J.; Zhu, X.; Vogelmann, J.E.; Gao, F.; Jin, S. A simple and effective method for filling gaps in landsat etm+ slc-off images. Remote Sens. Environ. 2011, 115, 1053-1064. [CrossRef]

61. Yu, X.; Guo, X.; Wu, Z. Land surface temperature retrieval from landsat 8 tirs-Comparison between radiative transfer equation-based method, split window algorithm and single channel method. Remote Sens. 2014, 6, 9829-9852. [CrossRef]

62. Jimenez-Munoz, J.C.; Sobrino, J.A.; Skokovic, D.; Mattar, C.; Cristobal, J. Land surface temperature retrieval methods from landsat-8 thermal infrared sensor data. IEEE Geosci. Remote Sens. Lett. 2014, 11, 1840-1843. [CrossRef]

63. Barsi, J.A.; Schott, J.R.; Hook, S.J.; Raqueno, N.G.; Markham, B.L.; Radocinski, R.G. Landsat-8 thermal infrared sensor (tirs) vicarious radiometric calibration. Remote Sens. 2014, 6, 11607-11626. [CrossRef]

64. Jiménez-Muñoz, J.C.; Sobrino, J.A. A generalized single-channel method for retrieving land surface temperature from remote sensing data. J. Geophys. Res. Atmos. 2003, 108. [CrossRef]

65. Sobrino, J.A.; Jiménez-Muñoz, J.C.; Sòria, G.; Romaguera, M.; Guanter, L.; Moreno, J.; Plaza, A.; Martínez, P. Land surface emissivity retrieval from different vnir and tir sensors. IEEE Trans. Geosci. Remote Sens. 2008, 46, 316-327. [CrossRef]

66. Tucker, C.J. Red and photographic infrared linear combinations for monitoring vegetation. Remote Sens. Environ. 1979, 8, 127-150. [CrossRef]

67. Huete, A.R. A soil-adjusted vegetation index (savi). Remote Sens. Environ. 1988, 25, 295-309. [CrossRef]

68. Gao, B.-C. Ndwi-A normalized difference water index for remote sensing of vegetation liquid water from space. Remote Sens. Environ. 1996, 58, 257-266. [CrossRef]

69. Zha, Y.; Gao, J.; Ni, S. Use of normalized difference built-up index in automatically mapping urban areas from tm imagery. Int. J. Remote Sens. 2003, 24, 583-594. [CrossRef]

70. Liang, S. Narrowband to broadband conversions of land surface albedo i: Algorithms. Remote Sens. Environ. 2001, 76, 213-238. [CrossRef]

71. Silva, B.B.D.; Braga, A.C.; Braga, C.C.; de Oliveira, L.M.; Montenegro, S.M.; Barbosa Junior, B. Procedures for calculation of the albedo with oli-landsat 8 images: Application to the brazilian semi-arid. Rev. Bras. Eng. Agrícola Ambient. 2016, 20, 3-8. [CrossRef]

72. Huang, C.; Wylie, B.; Yang, L.; Homer, C.; Zylstra, G. Derivation of a tasselled cap transformation based on landsat 7 at-satellite reflectance. Int. J. Remote Sens. 2002, 23, 1741-1748. [CrossRef]

73. Liu, Q.; Liu, G.; Huang, C.; Liu, S.; Zhao, J. A tasseled cap transformation for landsat 8 oli toa reflectance images. In Proceedings of the 2014 IEEE International Geoscience and Remote Sensing Symposium (IGARSS), Quebec City, QC, Canada, 13-18 July 2014; pp. 541-544.

74. Liu, Q.; Liu, G.; Huang, C.; Xie, C. Comparison of tasselled cap transformations based on the selective bands of landsat 8 oli toa reflectance images. Int. J. Remote Sens. 2015, 36, 417-441. [CrossRef] 
75. Dalal, S.; Shirodkar, P.; Jagtap, T.; Naik, B.; Rao, G. Evaluation of significant sources influencing the variation of water quality of kandla creek, gulf of katchchh, using pca. Environ. Monit. Assess. 2010, 163, 49-56. [CrossRef]

76. Vukovich, F.M.; Sherwell, J. An examination of the relationship between certain meteorological parameters and surface ozone variations in the baltimore-washington corridor. Atmos. Environ. 2003, 37, 971-981. [CrossRef]

77. Ouyang, Y.; Nkedi-Kizza, P.; Wu, Q.; Shinde, D.; Huang, C. Assessment of seasonal variations in surface water quality. Water Res. 2006, 40, 3800-3810. [CrossRef]

78. Mas, J.-F. Monitoring land-cover changes: A comparison of change detection techniques. Int. J. Remote Sens. 1999, 20, 139-152. [CrossRef]

79. Gaitani, N.; Burud, I.; Thiis, T.; Santamouris, M. High-resolution spectral mapping of urban thermal properties with unmanned aerial vehicles. Build. Environ. 2017, 121, 215-224. [CrossRef]

80. Vázquez-Jiménez, R.; Ramos-Bernal, R.N.; Romero-Calcerrada, R.; Arrogante-Funes, P.; Tizapa, S.S.; Novillo, C.J. Thresholding algorithm optimization for change detection to satellite imagery. In Colorimetry and Image Processing; IntechOpen: Gran Canaria, Spain, 2017.

81. Weng, Q.; Rajasekar, U.; Hu, X. Modeling urban heat islands and their relationship with impervious surface and vegetation abundance by using aster images. IEEE Trans. Geosci. Remote Sens. 2011, 49, 4080-4089. [CrossRef]

82. Jolliffe, I. Principal Component Analysis; Springer: Berlin/Heidelberg, Germany, 2011.

83. Hutcheson, G.D. Ordinary least-squares regression. In The SAGE Dictionary of Quantitative Management Research; Moutinho, L., Hutcheson, G.D., Eds.; Sage: London, UK, 2011; pp. 224-228.

84. Yang, Y.; Li, X.; Pan, X.; Zhang, Y.; Cao, C. Downscaling land surface temperature in complex regions by using multiple scale factors with adaptive thresholds. Sensors 2017, 17, 744. [CrossRef] [PubMed]

85. Srivastava, P.K.; Majumdar, T.; Bhattacharya, A.K. Surface temperature estimation in singhbhum shear zone of india using landsat-7 etm + thermal infrared data. Adv. Space Res. 2009, 43, 1563-1574. [CrossRef]

86. Qin, Q.; Zhang, N.; Nan, P.; Chai, L. Geothermal area detection using landsat etm+ thermal infrared data and its mechanistic analysis-A case study in Tengchong, China. Int. J. Appl. Earth Obs. 2011, 13, 552-559. [CrossRef]

87. Firozjaei, M.K.; Kiavarz, M.; Nematollahi, O.; Karimpour Reihan, M.; Alavipanah, S.K. An evaluation of energy balance parameters, and the relations between topographical and biophysical characteristics using the mountainous surface energy balance algorithm for land (SEBAL). Int. J. Remote Sens. 2019, 40, 5230-5260. [CrossRef]

88. Bindhu, V.; Narasimhan, B.; Sudheer, K. Development and verification of a non-linear disaggregation method (nl-distrad) to downscale modis land surface temperature to the spatial scale of landsat thermal data to estimate evapotranspiration. Remote Sens. Environ. 2013, 135, 118-129. [CrossRef]

89. Allen, R.G.; Trezza, R.; Tasumi, M. Analytical integrated functions for daily solar radiation on slopes. Agric. For. Meteorol. 2006, 139, 55-73. [CrossRef]

90. Kalogirou, S.A. Solar Energy Engineering: Processes and Systems; Academic Press: Cambridge, MA, USA, 2013.

91. Zhao, W.; Wu, H.; Yin, G.; Duan, S.-B. Normalization of the temporal effect on the modis land surface temperature product using random forest regression. ISPRS J. Photogramm. Remote Sens. 2019, 152, 109-118. [CrossRef]

92. Abdel-Rahman, E.M.; Ahmed, F.B.; Ismail, R. Random forest regression and spectral band selection for estimating sugarcane leaf nitrogen concentration using eo-1 hyperion hyperspectral data. Int. J. Remote Sens. 2013, 34, 712-728. [CrossRef]

93. Noi, P.T.; Degener, J.; Kappas, M. Comparison of multiple linear regression, cubist regression, and random forest algorithms to estimate daily air surface temperature from dynamic combinations of modis lst data. Remote Sens. 2017, 9, 398. [CrossRef]

94. Strobl, C.; Malley, J.; Tutz, G. An introduction to recursive partitioning: Rationale, application, and characteristics of classification and regression trees, bagging, and random forests. Psychol. Methods 2009, 14, 323-348. [CrossRef] [PubMed]

(C) 2019 by the authors. Licensee MDPI, Basel, Switzerland. This article is an open access article distributed under the terms and conditions of the Creative Commons Attribution (CC BY) license (http://creativecommons.org/licenses/by/4.0/). 